NBER WORKING PAPER SERIES

\title{
UNCOVERING THE HIDDEN EFFORT PROBLEM
}

\author{
Azi Ben-Rephael \\ Bruce I. Carlin \\ Zhi Da \\ Ryan D. Israelsen \\ Working Paper 28441 \\ http://www.nber.org/papers/w28441 \\ NATIONAL BUREAU OF ECONOMIC RESEARCH \\ 1050 Massachusetts Avenue \\ Cambridge, MA 02138 \\ February 2021
}

We are grateful for feedback from Tom Bates, Alex Butler, Alan Crane, Jeff Coles, David De Angelis, Gene Fama, Simon Gervais, Jessica Jeffers, Steve Kaplan, Mike Lemmon, William Mann, Kevin Murphy, Stefan Nagel, Lubos Pastor, David Robinson, James Weston, David Yermack, and Luigi Zingales. Also, we acknowledge helpful feedback from seminar participants at the University of Chicago, Washington University in St. Louis, University of Texas, Notre Dame, Drexel University, and Rice University, and conference attendees at the ASU Sonoran Winter Finance Conference the 2020 Northern Finance Meetings, and the 2021 American Finance Meetings. We also appreciate the advice and counsel from Richard Zansitis (Vice President and General Counsel for Rice University). This study was approved by the IRB at Rice University and by Bloomberg Finance L.P. The views expressed herein are those of the authors and do not necessarily reflect the views of the National Bureau of Economic Research.

NBER working papers are circulated for discussion and comment purposes. They have not been peer-reviewed or been subject to the review by the NBER Board of Directors that accompanies official NBER publications.

(C) 2021 by Azi Ben-Rephael, Bruce I. Carlin, Zhi Da, and Ryan D. Israelsen. All rights reserved. Short sections of text, not to exceed two paragraphs, may be quoted without explicit permission provided that full credit, including $(\odot$ notice, is given to the source. 
Uncovering the Hidden Effort Problem

Azi Ben-Rephael, Bruce I. Carlin, Zhi Da, and Ryan D. Israelsen

NBER Working Paper No. 28441

February 2021

JEL No. D22,D82,G32,M52

\section{ABSTRACT}

We use machine learning to analyze minute-by-minute Bloomberg online status data and study how the effort provision of top executives in public corporations affects firm value. While executives likely spend most of their time doing other activities, Bloomberg usage data allows us to characterize their work habits. We document a positive effect of effort on unexpected earnings, cumulative abnormal returns following firm earnings announcements, and credit default swap spreads. We form long-short, calendar-time, effort portfolios and show that they earn significant average daily returns. Finally, we revisit several agency issues that have received attention in the prior academic literature on executive compensation.

Azi Ben-Rephael

Rutgers Business School

1 Washington Park

Newark, NJ 07102

abenrephael@business.rutgers.edu

Bruce I. Carlin

Jones School of Business

Rice University

1900 Rice Boulevard

Houston, TX 77005

and NBER

carlin@ rice.edu
Zhi Da

University of Notre Dame

239 Mendoza College of Business

Notre Dame, Indiana 46556-5646

zda@nd.edu

Ryan D. Israelsen

Michigan State University

Broad College of Business

667 N Shaw Ln Rm 307

East Lansing, MI 48824

USA

israels4@msu.edu 


\section{Introduction}

The moral hazard problem due to hidden effort is ubiquitous in economics and two fundamental ideas are generally accepted. First, principals are tasked with an inference problem regarding their agent's effort provision. Second, they can (or should) try to ameliorate the conflict with compensation contracts or ownership grants (Holmstrom and Milgrom, 1987).

But studying whether this actually works in Corporate America or if high effort provision is indeed valuable is nearly impossible. If the principal in any organization cannot observe the effort provision made by their managers, it is unlikely that outsiders like an economic empiricist or a market investor would have better information. Both can perform statistical inference, much like the principal, based on compensation contracts and firm outcomes (e.g., stock prices or earnings). But these calculations are limited because they face the hidden action problem too.

How could one calibrate a manager's work activities without inducing an observer effect (i.e., changing executive behavior) or covertly spying on them? ${ }^{1}$ A good prospect would be to find something that is highly correlated with the time they spend working, like the amount of time their office lights are on (at home or work), their computer is active, or their office phone (cell phone) is in use. Certainly, none of these is perfect, but they do convey some information about an executive’s daily work habits.

In this paper, we hand-collect minute-by-minute usage data from personal Bloomberg accounts for CEO's, CFO's, and top executives from publicly traded firms, many of which are in the S\&P500 and are not financial firms. We use machine learning to estimate their work habits as measures of effort provision, and perform cross-sectional and time series tests to examine how effort affects firm value. We also revisit several agency issues that have received attention in the past, such as the effect of compensation discontinuities and leisure activities on executive behavior.

Bloomberg terminals are typically located at work, but its platform can be accessed remotely. It is not an attractive source of leisure. It is obvious by mere inspection of the platform that it is for work use and does not provide any sort of entertainment. But, three hundred and ninety-five firms (97 financial and 298 non-financial) in the S\&P500 use Bloomberg in their business activities and it is often used by executives in Corporate America as source of financial

\footnotetext{
${ }^{1}$ Direct monitoring has been used to assess how executives spend their time (e.g., Mintzberg, 1973; Bandiera, Hansen, Pratt, and Sadun, 2020). But explicit monitoring and self-reported data present obstacles when trying to quantify how compensation affects moral hazard problems like effort provision.
} 
information, and for risk management, investor relations, communications with analysts, and competitive industry analysis. $^{2}$

What is under-appreciated though, especially by academics, is that Bloomberg is also a powerful social network that significantly pre-dates platforms like Facebook. The platform gives all users access to each other via texting and encourages the exchange of information between traders and among corporate leaders. When individuals sign user agreements, they are given the opportunity to communicate with each other via messaging technology. Users are readily identified as "online” to others if they are logged into their personal account. So, whether someone is actively using the software is publicly observable.

We collect minute-by-minute user data during 2017-2020. Figure 1 provides an example of where we obtained this activity. ${ }^{3}$ The green dot by Michael Bloomberg's name indicates that he is actively using his personal account. If he were to become inactive for greater than 15 minutes, the dot would turn yellow. If an executive is offline, the dot is red, and if a telephone icon appears, it indicates he/she is using the mobile application.

We use this dataset to detect how often each executive is engaged in a work-related task and estimate the length of time they work each day. ${ }^{4}$ We do not use the intensity or total time on the terminal in our tests, because we expect top executives to have a diverse set of responsibilities that do not involve being on Bloomberg all day. But, as we describe, the machine learning algorithm that we employ uses the login patterns over time to describe typical work habits, which parameterizes their effort provision.

We start by providing evidence that supports the plausibility of Bloomberg usage as an effort measure. We show that Bloomberg activity spikes around earnings announcements for both CEO's and CFO's, and that its intensity of use was higher during the COVID pandemic when

\footnotetext{
${ }^{2}$ See https://www.bloomberg.com/professional/expertise/c-suite/

${ }^{3}$ It is important to note that we did not collect any private information about what the executives actually did on the terminal: we did not observe any information about messaging, news search, or trading-related activities. As we are only interested in the simple usage of the terminal as a proxy for work effort, we do not collect any sensitive information from corporate firms and keep all identities anonymous in our analysis.

${ }^{4}$ Use of this data was approved by Bloomberg Finance L.P. Additionally, we carefully reviewed the following contracts and disclosures with General Counsel at Rice University: Bloomberg's user agreement with Michigan State, Bloomberg's Terms of Service, and Bloomberg's Privacy Policy. See "Disclosure of Your Personal Information" in https://www.bloomberg.com/notices/privacy/ and https://www.bloomberg.com/notices/tos/. Once subjects were matched to compensation and firm information, their identities were anonymized and the investigators were made blind as to particular identities and results. We do not disclose subject identities in any of the results reported in this paper.
} 
exectuives were confined at home. Importantly, we show that the account activity that we measure directly depends on the owner of each account, not someone else at the firm. We amass a dataset of events where an executive is participating or speaking, and document almost no simultaneous activity on the Bloomberg platform. For example, we show that during analyst and investor days, the Bloomberg account for every single executive in our sample is inactive.

Figure 2 shows a histogram of the annual daily usage for an executive in our sample. For each minute of a 24-hour period, the y-axis measures the probability that the executive is active on their Bloomberg account during the course of a year. As is common in our data, there is a peak mid-morning and in the afternoon, with a dip during lunchtime. The machine learning algorithm uses the observation that this function appears to be similar to a mixed distribution of two normal distributions, one for the morning and one in the afternoon. The estimation-maximization (EM) algorithm provides estimates of the underlying moments of the two distributions and we construct a distance measure called the Gaussian Mixture Length (GML) to proxy for the length of each executive's workday. ${ }^{5}$

We investigate the effect of effort on firm performance in several ways. To make causal statements, we include individual executive fixed effects to control for all time-invariant, unobserved characteristics. We also include measures of insider trading to account for the influence that private information potentially has on earnings surprises and abnormal returns. First, using a measure of standardized unexpected earnings (SUE; Foster, Olsen, and Shevlin, 1984), we find that higher effort is associated with subsequent earnings surprises.

Then, we show that effort provision has a positive and persistent effect on cumulative abnormal returns (CAR) following earnings announcements. A one-hour increase in the average workday length is associated with a CAR of 25-50 basis points that persists for 10 weeks following the announcement. Motivated by this result, we form calendar-time portfolios using a trading strategy based on extreme changes in quarterly executive effort relative to past effort. We document that a risk-adjusted, long-short effort portfolio yields 7.33 basis points per day (37 bps over 5 days), a quantity that is plausible, robust, and statistically significant.

Not surprisingly, fifty percent of the firms in our sample are from the finance industry. One concern is that this is driving our results. To address this, we separately analyze the subset of non-

\footnotetext{
${ }^{5}$ Besides $G M L$, as we discuss in the paper, we have also constructed three other measures of daily workday effort and find our main results to be robust.
} 
financial firms and find that our SUE and CAR results are at least as strong, if not stronger. For non-financial firms, a one-hour increase in the average GML is associated with a CAR of 80-100 basis points at 7-10 weeks following an earnings announcement.

Another consideration is that executives are frequently compensated based on their firm's earnings or stock price. These measures might be subject to some degree of manipulation. To address this, we collect data on credit default swaps that are traded on the firms in our sample. To our knowledge, no executive is explicitly given incentives to improve the default risk of their firm as measured by the credit default swap spread. Consistent with the earnings findings, we find that an increase in average GML in one quarter is associated with an improvement in the firm's CDS spreads in the next quarter. ${ }^{6}$

Our ability to estimate executive effort allows us to investigate several agency issues that have received attention in the academic literature. The first is how executives behave when there are discontinuities in their compensation (Healy, 1985; Degeorge, Patel, and Zeckhauser, 1999; Murphy, 2000). ${ }^{7}$ The mere presence of goals and targets induces kinks, whereby earning compensation may be outside an executive's locus of control.

To investigate this, we study changes in executive GML in response to firm performance within the fiscal year. Specifically, we consider whether firm performance in the $1^{\text {st }}$ half of the year affects whether earning a cash bonus is within an executive's locus of control for the second half. ${ }^{8}$ We document a large, positive, and statistically significant change in $G M L$ when midyear performance is on pace with set targets. But, when midyear earnings are either exceeding or lagging behind compensation targets, executives employ less effort. Since the targets do not change, but beliefs about achieving them do, this within-executive result is a causal effect.

The next agency issue deals with the possibility that executives engage in leisure activities, rather than employ effort (Yermack, 2014; Biggerstaff, Cicero, and Puckett, 2017). ${ }^{9}$ To capture

\footnotetext{
${ }^{6}$ The magnitudes are small, but statistically significant. A one hour increase in average GML is associated with a reduction of -1.50 basis points. Firms in our sample have an average of $\$ 34.7$ billion in long-term debt. This amounts to an annual savings of $\$ 5.2$ million. While small, this does appear to be an economically plausible effect.

${ }^{7}$ For example, Healy (1985) shows that floors and caps in compensation plans give executives the incentive to manage earnings.

${ }^{8}$ For the executives in our sample, their compensation contracts did not change within the year. We confirm this by reviewing 8-K filings for the firms in our sample and screening for disclosures under item 5.02.

${ }^{9}$ Both Yermack (2014) and Biggerstaff, Cicero, and Puckett (2017) find evidence consistent with an agency cost hypothesis by studying leisure activities like vacation travel and golf habits. However, both acknowledge that it may be impossible to precisely identify what business activities potentially took place during those times because monitoring executive behavior explicitly is challenging.
} 
conditions that may encourage such activity, we examine the local weather. Specifically, we study cloud cover, daylight hours, precipitation, as well an adjusted temperature index - the Universal Thermal Climate Index (UTCI) - that is designed to capture the human physiological reaction to the outdoor thermal environment (i.e., temperature, radiation, humidity, and wind speed). ${ }^{10}$ We find that executive effort is reduced during quarters in which weather is more favorable for outdoor activities. We find the result to be the most pronounced among CEOs and CFOs where a onestandard-deviation improvement in good weather is associated with 18-20 fewer hours in the office during the quarter.

The remainder of the paper is organized as follows. In Section 2, we describe the data collection and provide sample statistics. There we construct our variables of interest and provide support for using our measure of effort. Section 3 provides an analysis of executive effort and firm outcomes. In Section 4, we study agency and other incentives to employ effort. Section 5 concludes.

\section{Data and Sample Statistics}

\subsection{Sample Construction and Summary Statistics}

User Data: When Bloomberg users are assigned accounts, the company records their "status” by default. $^{11}$ Status is either designated as “online”, “idle”, “offline”, or “mobile”. When users first $\log$ on to the platform, their status changes from offline to online, and it remains that way while they use Bloomberg. However, if they stop using it for 15 minutes, the user's status automatically changes to "idle”. Eventually, and depending on the users' settings, a user is logged off after a long period of inactivity. Also, when users are logged in via the "Bloomberg Anywhere" application on their mobile device, the status is listed as "mobile”. While using the mobile app, access to an assigned desktop terminal is restricted, so there is no possibility of double-counting.

Other users of the terminal can detect the status of any other Bloomberg user by employing the "PEOP” function, the "BIO" function, or by directly navigating to a user's profile. Figure 1 gives an example of a profile search for Michael Bloomberg. The green dot by Michael Bloomberg's name indicates that he is online and active. Other status indicators are as follows: a

\footnotetext{
${ }^{10}$ See Bröde et al. (2012).

${ }^{11}$ Users may set their profile status to “private”, but only $9.5 \%$ of Executives do so.
} 
red dot means that a user is offline, a yellow dot means that a user is idle, and a gray dot indicates that a user has chosen to be private. If a user is online via the mobile app, a mobile phone icon appears. Note the full functionality of the software to contact people who use the platform.

During 2017-2020, we used the profile search and followed 2,734 users with executive in their title (e.g., “Chief Financial Officer”, “Chief Executive Officer”, etc.). We recorded their name, title, location, firm name, and followed their user status continuously over the entire time series. At no time did we collect the content of their use: we did not observe their text messaging, news search, or trading activity. The only data we collected is the time that each person actually uses the platform.

The majority of the 2,734 executives in our user dataset work in private firms. Of that number, 474 are "named executives" at 308 unique public firms. Executives list their geographic location in their profile. While there are concentrations in the Northeast, Texas, Chicago, and California, there is a large geographic dispersion. Forty-three states plus the District of Columbia are represented. When we analyze the effect of effort on abnormal returns, we analyze 1128 executive-quarter observations. To study the effect of contracting on effort, we use the ISS Incentive Lab database, which collects compensation information from proxy statements and provides it in tabular format. After merging the set of named executives with the Incentive Lab database, we are left with 252 top executives from 174 publicly-traded companies, and 520 executive-year observations. In our sample, $27 \%$ of executive-year observations are for CEOs while $45 \%$ are for CFOs. The remainder are named executives with other roles.

Table 1 provides summary statistics at the executive-fiscal year level for the executives in our sample. Panel 1.A presents statistics on firm characteristics. Size is the market capitalization (in millions of dollars) of the firm's stock (CRSP item prc times shrout) at the end of the previous fiscal year; $Q$ is Tobin's Q; leverage is long term debt (Compustat item dltt) plus debt in current liabilities (Compustat item dlc) all divided by total assets (Compustat item at); productivity is revenues (Compustat item sale) divided by total assets. The mean market capitalization for the executives’ firms is \$43 Billion, with a median of \$12.9 Billion. We use the natural logarithm of size in our regressions (In_size). Tobin's Q is about 1.58, on average. The average ratios of debt to assets is 0.31 , and average ratio of revenues to assets is 0.35 .

Panel 1.B breaks executive-year observations into industries based on the 4-digit SIC code of their firms according to the Fama-French 12 industry classifications. The panel shows that 
roughly half of the observations are from executives at financial firms, which is not surprising given the nature of Bloomberg terminals. The next most common industry (12.5\% of the observations) is "Other", which consists of firms in industries with fewer firms that do not fit into the remaining 11 industries. "Energy" is the third most common industry (9.2\% of observations), followed by Utilities (6.3\%), and Healthcare (6.2\%). Business Equipment, Chemicals, Manufacturing, Telecommunications, Consumer NonDurables, Consumer Durables, and Wholesale and Retail collectively make up the remaining $11.2 \%$ of observations.

\subsection{Patterns of Bloomberg Usage}

First, we examine patterns in the raw activity data and then provide evidence that the user data captures a plausible measure of effort provision. While we collect data through 2020, much of our analysis uses data from 2017-2019. This is due to the need to collect other variables and the highly unusual events that arose during the COVID pandemic.

Table 2 provides some summary statistics of user activity. For the 520 executive-year periods that we collect between September 2017 and December 2019, we have an average of 178 days of data per executive-year. On average, 129 of those are workdays, which we define as Monday through Friday. There is an average of 31 weeks per executive-year.

The "Bloomberg Usage" section of Table 2 provides statistics for active platform and mobile usage for various timeframes. On average, executives in our sample are actively using Bloomberg for 6.92 hours per week and they spend much less time on the mobile app than on the platform - about 30 minutes per week, on average. They spend very little time on Bloomberg on the weekend or at night, which we define as $6 \mathrm{pm}$ on a given day to 3am the following morning. ${ }^{12}$ Also, executives tend to spend little time on Bloomberg on holidays, about thirty minutes per day on average.

These patterns tend to suggest that Bloomberg use is a work activity, rather than one of leisure. To see this visually, Figure 3 presents the average percentage of executives that actively use the platform during each minute of workdays. Active use is very limited, on average, before about 7am, and after about 6pm. There is also a drop in activity during the lunch hour. Thus, the general activity level is concentrated during the traditional 9 to 5 workday. In Figure 4, we examine

\footnotetext{
${ }^{12}$ These times are based on each executive's local time. We extend the nighttime window to include 3 am in case they work late and because activity on the platform is at a daily minimum at 3am.
} 
average activity throughout the week. The histogram shows that activity is generally higher at the beginning of the workweek and declines throughout the week. During a typical workweek, effort is typically lowest on Friday. ${ }^{13}$

To further explore the plausibility of Bloomberg usage as a proxy for time spent at work, we next examine whether activity is higher on days with important firm-level events. Figure 5 Panel A shows the average number of active hours in event time for all executives, relative to their firm's quarterly earnings announcement. A trend line is fitted (using OLS) separately for the periods before and after the announcement date. The day with the highest amount of activity is the earnings announcement date. Following the announcement, activity drops and steadily increases until the next announcement. Panel B shows the same figure for the subset of Chief Financial Officers, where the pattern is more pronounced. Panel C presents the figure for the subset of CEOs. Again, activity is the highest on the announcement date, but is also high the following day. It is also constructive how usage changed during the COVID-19 pandemic of 2020, once executives experienced restricted travel, less access to leisure activities, and more time at home. Figure 6 provides a comparison of daily activity in 2020 with previous years (2018 and 2019) for the months of March, April, May, and June. By inspection, it is apparent that Bloomberg activity increased during the pandemic and use of the platform extended later into the evening hours. These findings are consistent with more remote work habits and substituting time on a computer for travel or leisure when they are made less available. Also, this appears to provide support for the idea that Bloomberg usage is in fact helpful in describing the work habits of its users.

Finally, we attempt to rule out the possibility that an executive's personal account is being accessed by other people such as their assistants or underlings. To investigate this, we look at usage habits by excecutives during key firm level events where we they are not only likely to be in attendance, but speaking as an active participant. These include shareholder meetings, earnings releases, and conference calls.

We collect this information using the Bloomberg corporate events calendar (function "EVTS") which includes the name, type, and timing of each event as well as a description. Categories include earnings calls, earnings releases, annual meetings, investment banking conferences/presentations, analst days, and investor days, among others. For each event for which we know the date and start time, we examine executive activity on the terminal during the first 30

\footnotetext{
${ }^{13}$ In the figure, we use GML as our measure of activity. We describe this variable in detail in Section 2.3.
} 
minutes of the event. We use a short window since the lengths of the events vary and the end-time is not always documented. We count the number of executives who are not active on the terminal at any point during that 30 minute window and aggregate by executive role and event.

We use Bloomberg's categories and descriptions to categorize events. For the investment banking conferences/presentations and analyst and investor days, we examine the event transcripts on Factiva in order to determine who was present. Executives who were not present are excluded from those two categories. The vast majority of annual meetings do not have transcripts on Factiva. Table 3 provides terminal usage statistics for each of these categories.

The results are striking. For the analyst and investor days, the Bloomberg account for every every single executive is inactive. During investment banking conferences, more than 99\% of excecutives are not active on the terminal. In the full sample of almost 1,500 observations, there are only 6 cases (4 unique executives) where there is activity on an executives' Bloomberg account during an event. For annual meetings, more than $90 \%$ of the time, there is no activity on the terminal for CEOs, CFOs, and other executives. These results are overwhelmingly consistent with the notion that activity on the terminal is typically carried out by the executive him- or herself.

For reference, Table 3 also presents results for two other events where the executive may or may not have access to the Bloomberg terminal, depending on the situation - earnings releases and earnings calls. The data suggest that there is relatively less inactivity during an earnings release: $74.6 \%$ of CEOs are inactive, $72.4 \%$ for CFOs, and $81.3 \%$ for other excecutives. Finally, during earnings calls, about $87 \%$ of CEOs, $89 \%$ of CFOs and $87 \%$ of other executives are not actively using their Bloomberg account.

\subsection{Effort Measures and Machine Learning}

At first glance, it might be attractive to create simple measures based on examining individual days to evaluate when an executive is on the terminal, such as the average number of days per week or the average daily time between the first and last login. However, while these measures provide similar results and are intuitive, they underestimate the executives' work habits if executives log into Bloomberg intermittently and at different times of the day. This is why we aggregate each executive's activity across a fixed time period (one year or one quarter) and use unsupervised machine learning to construct a distributional measure that better controls for the intermittent, and perhaps erratic, usage of the terminal. 
Inspection of Figures 2 and 3 reveals that the overall usage pattern looks like a distribution that results from the mixture of two normal distributions, one for the morning and one after lunch. Clearly, the pattern in the data is not derived from a distribution per se, but we use this observation to construct our primary workday length measure, Gaussian Mixture Length (GML), which is based on a mixture of normal distributions that we construct as follows.

For each executive and year, we know the probability $P_{\min }^{j}$ that the executive is logged on every minute of the day $j \in J \equiv\{12: 00 \mathrm{am}, 11: 59 \mathrm{pm}\}$. We construct a pdf by computing

$$
p_{\min }^{i}=\frac{P_{\min }^{i}}{\sum_{J} P_{\min }^{j}}
$$

By construction, $\Sigma_{J} p_{\min }^{j}=1$. We then assume that the constructed distribution is a mixture of two normal distributions $k \in\{1,2\}$, each with mean $\mu_{k}$ and variance $\sigma_{k}^{2}$, where $\mu_{2}>\mu_{1}$. This captures the idea that executives may have different morning and afternoon work habits. Also, as described above, a dip in activity around lunchtime is very frequent in our sample.

For the mixed distribution, there is a probability $q$ that any realization is drawn from distribution 1 and probability $(1-q)$ that it was drawn from distribution 2 . The mixed distribution has mean $\mu_{1,2}$ and variance $\sigma_{1,2}^{2}$, which can be measured for each executive. We also have the following relationships:

$$
\begin{gathered}
\mu_{1,2}=q \mu_{1}+(1-q) \mu_{2} \\
\left.\sigma_{1,2}^{2}=q \sigma_{1}^{2}+(1-q) \sigma_{2}^{2}+q 1-q\right)\left(\mu_{2}-\mu_{1}\right)^{2}
\end{gathered}
$$

Using these two equations, we perform an expectation-maximization (EM) algorithm to estimate all five parameters for each executive $\left(q, \mu_{1}, \mu_{2}, \sigma_{1}^{2}, \sigma_{2}^{2}\right)$.

The EM algorithm consists of two steps: the estimation step (E-Step) and the maximization step (M-Step). In the E-Step, the expectation of the log likelihood function is calculated for a given set of candidate parameters. In the M-Step, the parameters are re-chosen in order to maximize the expectation. The process continues, iterating between the E-Step and the M-Step until the sequence converges. In our case, the likelihood function involves the likelihood of observing the data given that there are two unobservable Gaussian distributions generating the data. We implement the procedure using the scikit-learn library for Python. ${ }^{14}$

\footnotetext{
${ }^{14}$ We use the sklearn.mixture.GaussianMixture method with a convergence threshold of 0.001 and K-Means clustering to initialize the parameters.
} 
For each executive, we create the daytime length measure $G M L$ with the estimated vector $\left(\hat{\mu}_{1}, \hat{\mu}_{2}, \hat{\sigma}_{1}^{2}, \hat{\sigma}_{2}^{2}\right)$, which is computed as follows:

$$
G M L=\left(\hat{\mu}_{2}-\hat{\mu}_{1}\right)+\hat{\sigma}_{1}+\hat{\sigma}_{2}
$$

The distance GML measures the difference between the means of the two distributions and adds a standard deviation on each side. As such, it allows for the more diverse work habits that are present in our executive sample.

Figure 7 provides three visual examples of how GML is constructed. The shaded blue area is each executive's underlying Bloomberg activity, which has been converted into a pdf. The two yellow curves are the normal distributions derived from the EM algorithm and the red curve is the resultant mixed distribution. As can be appreciated, the estimated mixture closely approximates the underlying activity, and captures differences in morning versus afternoon work activity. The variable $G M L$ is the distance between the two solid lines in the plot.

The last panel in Table 2 also provides summary statistics for GML. The mean level of $G M L$ during the sample is about 9.5 hours with a standard deviation of about 2 hours. This is likely to be a superior measure of executive work habits as its magnitude is more consistent with what we would intuitively expect. Figure 8 provides a histogram that provides a distribution of $G M L$ for executives in our sample.

\section{Effort Provision and Firm Outcomes}

Now, we address a long-standing question whether and how much incentives and effort provision improve firm value. From a theoretical perspective, higher effort should increase the probability of good outcomes. Alternatively, effort may be inefficient in many cases or misguided. Either way, as Murphy (1999) points out, studying this has been challenging in the past: because changes in executive compensation or ownership grants are public information, equity prices adjust quickly (i.e., markets are efficient). Therefore, previous studies have been constrained because investigators had to connect incentives to firm value directly, without measuring the intermediate step of effort provision. That is, investigators had no better information than equity market participants. However, since we are able to measure executive effort directly here and this is not observable to (or followed by) equity market participants, we can now revisit these issues.

We start by examining whether executives' effort provision during the fiscal quarter affects

firm earnings surprises. We use Standardized Unexpected Earnings (SUE), which is defined as the 
difference in the current quarterly earnings per share and the earnings per share 4 quarters prior, divided by the standard deviation of these differences measured over the previous eight quarters (Foster, Olsen, and Shevlin, 1984).

The independent variable is $D \_G M L$, which is defined as the difference in $G M L$ during the fiscal quarter minus the same measure during the fiscal quarter 4 quarters prior. In our regression, we focus on CEOs and CFOs and include measures of insider trading to control for private information that may be related to both effort provision and earnings. The variables $D \_p u r c h a s e$ and $D \_$sell are defined as the change in the log value of open market insider purchases and sells that the executive made, relative to 4 quarters prior. Two analogous variables D_purchase_all and D_sell_all capture changes in buying and selling by all insiders at the firm. Because we take differences in both the key independent and dependent variables, we are in essence studying a within-executive effect that controls for time-invariant, unobservable characteristics. ${ }^{15}$

According to Table 4, effort has a positive effect on SUE in all specifications. Roughly, a one standard deviation increase in D_GML leads to a 0.13 standard deviation increase in SUE. In the final specification of Table 4, we examine whether this result is present in non-financial firms, which make up about half of the sample. The results are significant and the point estimates are in fact larger when focusing on this subset of executives. ${ }^{16}$

Next, we study the effect of effort provision on cumulative abnormal returns (CARs) around firm earnings announcements. To measure abnormal returns, we use a Fama French 3Factor model to estimate factor loadings using a year of past returns (after skipping the most recent week) and create daily alphas. Then, we regress cumulative abnormal returns on GML from day 1 post-earnings announcement through 50 trading days (10 weeks), just prior to the next earnings announcement season. We include standardized unexpected earnings, SUE, to capture the impact of the earnings surprise on returns. Additionally, to capture information that may be known to insiders at the firm, but not yet public, we include our four measures of insider trading by the executive and other insiders (log_purchase, log_sell, log_purchase_all, and log_sell_all). We include executive individual fixed effects to control for time-invariant executive characteristics.

\footnotetext{
${ }^{15}$ We have also run regressions using quarterly GML levels with an executive fixed effects and find similar qualitative results.

${ }^{16}$ In untabulated resuts, we verify that our results also hold for non-financial firms using the first 7 specifications from Table 3.
} 
Table 5 shows that effort has a positive and persistent effect on returns. Panel 4.A examines all executives. The coefficients indicate that an increase in the length of the executive's workday by an hour is associated with a one-day abnormal return of 27.35 basis points. This increases over time and plateaus in a persistent 30-50 basis point CAR at 4-10 weeks. In Panel 4.B, we focus on executives at non-financial firms and find larger coefficients, though statistical significance is slightly lower over some horizons. These findings imply that unobserved effort that is not fully anticipated by an efficient market becomes incorporated into asset prices over time. Before now, where hidden effort was undetectable, this effect could not be appreciated. But, as we document, it is significant and independent of other executive attributes.

Motivated by the results in Table 5, we study the effect of effort on stock returns by forming calendar-time portfolios. We form portfolios using an implementable trading strategy based on extreme changes in quarterly executive effort relative to past effort. We create two portfolios, High_Effort, and Low_Effort. To be included in the high effort portfolio on a given day, we require (1) the change in $G M L$ for a stock's executive relative to $G M L$ four quarters prior to be in the top $10 \%$ for all executives for the same fiscal quarter end; and (2) the earnings announcement must have occurred within the past five trading days. The low effort portfolio is defined analogously, with the change in GML in the bottom $10 \%$ of all executives with the same fiscal quarter end. To reduce noise, when there are fewer than 2 stocks satisfying the two criteria on a given day, we substitute the risk free rate of return. Portfolio returns are value-weighted using each stock's market capitalization. We also form a portfolio that is long High_Effort and short Low_Effort. Both raw returns and risk-adjusted returns are reported. We use the Fama-French 3-factor model to adjust for risk. Factor loadings are estimated using a year of past daily stock returns (skipping the most recent week).

Table 6 presents the mean returns and standard errors in basis points per day. According to the results, the risk-adjusted long-short portfolio yields 7.33 basis points per day, or 37 bps over 5 days. This quantity is plausible and statistically significant.

One concern that might arise is that measuring the effect of effort on firm value using earnings or stock prices might be confounded by the fact that executives are typically given bonuses based on these metrics. In some circumstances, these quantities may be subject to manipulation. To address this, we study the relationship between $G M L$ and a firm's credit default 
swap spread. To our knowledge, no executive in our sample is compensated based on this, so it is not subject to management or manipulation.

We obtain CDS spread data from DataStream for the firms in our sample. We use the 5year CDS contracts, which have the broadest coverage. For each firm and quarter, we keep the spread quote from the last available day in the quarter. Since not all firms have active contracts during our sample period, our final sample includes 574 observations over 89 executives and 57 firms.

We report the results in Table 7, where we run regressions of firm CDS spreads in quarter $t+1$ on executive effort (GML) in quarter $t$, the firm's CDS spread (Spread) in quarter $t$, measures of insider trading in quarter $t$, and other firm characteristics. In Specifications 1-3, we only include Spread during quarter $\mathrm{t}$ and the GML during quarter t. A one hour increase in GML is associated with a reduction of -0.79 to -0.929 basis points in CDS spreads. Once we control for firm characteristics and include executive fixed effects (Specification 5), the magnitudes increase to negative 1.50 basis points. Including executive fixed effects ensures that we measure the impact of the individual executive effort on CDS spreads.

Next, controlling for insider trading activity during quarter $t$ (Specifications 6 and 7) does not alter our findings. This alleviates the concerns that GML is high (or low) due to the firm performance during the quarter, which is associated with subsequent CDS spreads. In the last two specificaitons we exclude financial firms. Note that the coefficient estimates are not materially different from what is reported in the other specificaitons. However, the low number of observations makes the estimation noiser, which reduces the statistical significance levels. Finally, although we use an AR1 model throughout our specifications (i.e., controlling for Spread t), a first differences model (i.e., Spread $t+1$ - Spread $t$ ) virtually provides the same set of results.

\section{Effort Provision and Agency}

\subsection{Incentives and the Locus of Control}

Healy (1985) was the first to consider how executives behave when there are discontinuities in their compensation. When targets and goals are included in employment contracts, this introduces kinks into the compensation that executives may earn based on performance. Healy (1985) and others focused on how these discontinuities affected earnings 
management and investment within the firm (Degeorge, Patel, and Zeckhauser, 1999; Murphy, 2000).

A natural question to consider is how executives employ effort in similar circumstances. What is at issue is whether earning more money is within their locus of control. If firm performance is such that an executive is far from attaining a goal or is well past a target, then employing extra effort is unlikely to yield a marginal benefit. In such cases, earning compensation is outside of their locus of control. In contrast, if an executive is on pace to earn extra compensation (i.e., at a compensation kink), there is a higher marginal benefit of effort and securing extra compensation is within their locus of control. ${ }^{17}$

In the Definitive Proxy Statement (SEC form DEF 14A), public firms disclose their compensation contracts from the previous fiscal year for "named executives". Proxy statements are filed in advance of each firm's annual shareholder meeting, which typically are released during Q1. Item 402(a)(3) in SEC Regulation S-K defines the named executives as the CEO, the CFO, and at least three other executives with the highest compensation, and up to two former executives that served during the year and would have been in the previous category.

Proxy statements provide information on the type of compensation that each executive would receive - fixed wage, cash bonus, equity, option grant - as well as the target metric that would be used to compute end-of-year compensation (e.g., EBITDA, EPS, or Sales). While each proxy statement is backward looking, this allows us to study how ex ante contracting affects subsequent effort. For example, the 2019 proxy statement for a particular firm describes the compensation package and goals that its top executives received at the beginning of 2018.

For our purposes here, we use the ISS Incentive Lab database, which collects compensation information from proxy statements and provides it in tabular format. After merging the set of named executives with the Incentive Lab database with our Bloomberg data, we are left with 252 top executives from 174 publicly-traded companies, and 520 executive-year observations.

Table 8 provides statistics on these executives' compensation contracts. We define the following variables: value_stock_owned as the dollar value of the executive's stockholdings in the firm measured using price at the beginning of the fiscal year; salary is the executives' fixed salary

\footnotetext{
${ }^{17}$ As noted earlier, Healy (1985) describes this as the presence of floors and caps in compensation plans. An executive is outside their locus of control when they earn the floor or the cap and are well away from the incentive zone of their compensation scheme.
} 
during the fiscal year; cash_perf is the target dollar amount of the cash-based performance incentive bonus from the executive’s compensation contract for the fiscal year; stock_perf is the target dollar amount of the stock-based performance incentive bonus from the contract; stock_time and option_time are the values of the time-based stock and option grants, respectively, from the contract; Predicted compensation, pred_comp, is the sum of salary, cash_perf, stock_perf, stock_time, and option_time.

The top section of Table 8 indicates that $27 \%$ of executive-year observations are for CEOs while $45 \%$ are for CFOs. The remainder are named executives with other roles. The middle section of the panel provides summary statistics on compensation contracts. The mean value of the firm's own stock held by the executive is about $\$ 69$ Million, with a median of \$10.7 Million. Executives in the sample own about $0.77 \%$ of the firm, on average, but this is highly skewed with a median of only $0.07 \%$ The average annual predicted compensation is roughly $\$ 7.2$ million, and is broken into incentive compensation of roughly $\$ 3.7$ million that depends on attaining particular targets (cash_perf and stock_perf) and fixed compensation of roughly $\$ 3.5$ million that is guaranteed while the executive is employed by the firm (salary, stock_time, and option_time).

The final section of Table 8 provides a breakdown of the average weights of the metric types that determine the performance-based cash bonuses. While Incentive Lab provides many metrics (e.g., EBIT, customer satisfaction, etc.) as well as the metric types (e.g., Accounting), it does not provide the value-weight of each metric in the compensation formula. That is, for a particular executive, Incentive Lab determines the frequency with which a target or metric is used, not the proportion of the bonus that is linked to that particular measure. Consequently, we gather this information manually from the proxy statements. We find that accounting metrics make up about $62.8 \%$ of the metric types in the performance formulas in our sample. Metrics in the "Other" category make up about $27.6 \%$ of the formulas, on average. These are non-accounting based metrics that are typically industry- or firm-specific. Individual (stock price) performance makes up about $7.1 \%(2.5 \%)$ of the weight on average in our sample.

The way we investigate the effect of locus of control on effort is to examine changes in $G M L$ in response to firm performance within a fiscal year. Specifically, we study whether executive effort varies based on how close or far away from the targets firm performacnce is as the year goes on. When achieving bonuses is within the locus of control for an executive, we would expect them to exert more effort to secure higher compensation. 
While compensation contracts are known to executives in advance and are typically not subsequently changed, firms do occasionally modify contracts during the year for various reasons. Such material changes necessitate the filing of Form 8-K with the SEC. If these changes are present in our sample, it may affect the interpretation of our results. To address this issue, we examine all 8-K filings issued by firms from the sample used in Table 9. We focus on Item 5.02 in the 8-K which includes changes in compensation. Within that subset of filings, we identify those that include the words "compensation”, “change” or "modify”. Next, we carefully read the resulting filings to identify the exact nature of the event that triggered the 8-K as well as the specific executive associated with the event, if any. We find no evidence of any changes in contracts during the year in this sample.

We proceed to examine whether and when executives increase effort in the $2^{\text {nd }}$ half of the fiscal year, in response to firm performance in the $1^{\text {st }}$ half. We posit that when earnings per share in the first half of the year are on pace to finish close to the annual EPS target specified in the executive's cash bonus contract, executives will employ more effort to ensure that they attain their set EPS goals. For each executive whose cash bonus contract includes an earnings-per-share target, and for whom we have Bloomberg profile activity data for at least one fiscal quarter in the first half of the year and one quarter in the second half of the year, we measure the quantity $\mid 2 *\left(E P S_{Q 1}+E P S_{Q 2}\right)-E P S$ Target $\mid / E P S$ Target, where $E P S_{Q 1}$ and $E P S_{Q 2}$ are the firm's earnings per share in the $1^{\text {st }}$ and $2^{\text {nd }}$ fiscal quarter, and EPS Target is the executive's annual EPS target. This measures the absolute percentage projected deviation from the earnings target based on the first half of the year. The variable target_1_pct is equal to 1 when this quantity is less than $1 \%$ and 0 otherwise.

In Table 9, we regress the change in GML from the first half of the fiscal year to the second half on the interaction between target_1_pct and pct_cash_perf and other control variables. The coefficient on the interaction term is positive, large in magnitude, and statistically significant. This implies that when a firm's midyear performance is far from compensation targets (high or low), and achievement of a bonus is outside their locus of control, they employ less effort in the second half of the year. It is when success or failure is within their potential control that they exert more 
effort. Also, because we study changes in $G M L$ - a within-executive effect - this supports a causal relationship.

\subsection{Effort and Leisure}

As noted earlier, both Yermack (2014) and Biggerstaff, Cicero, and Puckett (2017) study leisure activities like vacation travel and golf habits and find evidence consistent with an agency cost hypothesis. Here, we add to this by studying the effect of weather conditions on effort provision. The primary question is whether executives tend to shirk when weather conditions make it attractive to engage in outside activities.

Clearly, this will depend on the locale in which the executive tends to reside. For example, a 50-degree, partly cloudy day in February will be perceived differently by an executive who resides in Chicago than one who is in San Diego. So, simply regressing temperatures or sunny days on effort provision is insufficient to capture executives' tendencies to employ less effort.

To this end, we construct a comfort/weather measure based on local weather conditions. We use the Universal Thermal Climate Index (UTCI) which is designed to capture the human physiological reaction to the outdoor thermal environment (i.e., temperature, radiation, humidity, and wind speed; Bröde et al., 2012). In contrast to other comfort indexes, it was designed to capture thermal comfort in an outdoor setting. Moreover, it's highly correlated with survey-based measures of human thermal comfort (e.g., Zare et al., 2018).

Using meteorological data from the website Weather Underground, we gather temperature, humidity, and wind speed data in order to calculate UTCI. ${ }^{18}$ We identify the hours during the quarter in which UTCI falls in the "thermal comfort zone", which is between $18^{\circ} \mathrm{C}$ and $26^{\circ} \mathrm{C}$ $\left(64.4^{\circ} \mathrm{F}\right.$ to $\left.78.8^{\circ} \mathrm{F}\right){ }^{19}$ Additionally, we gather data from Weather Underground on precipitation, cloud cover, and daylight hours. Then, we create the variable good_weather which is defined as the percentage of hours during a time interval in which (a) UTCI is in the "thermal comfort zone", (b) there is no precipitation, (b) the sky is not overcast, and (c) and the sun is up.

For illustrative purposes, Figure 9 plots good_weather at the month frequency for 4 cities - San Diego, CA, Honolulu, HI, New York, NY, and Houston, TX. The figure shows that the

\footnotetext{
${ }^{18}$ To calculate UTCI, we use the Python pythermalcomfort package (Tartarini and Schiavon, 2020).

${ }^{19}$ See The Commission for Thermal Physiology of the International Union of Physiological Sciences (2003) and Bröde et al., 2012
} 
percentage of hours considered to be "good" varies greatly by location and by time. Summer months in New York and San Diego tend to have the most good weather hours. By contrast, in Honolulu and Houston, summer months are too hot or humid to fall within the thermal comfort zone. In those cities, spring, fall, or winter (especially in Honolulu) tend to provide more opportunity to enjoy the weather. Across the 1,593 executive-quarter observations in our sample, good_weather has an mean (median) of 8.6\% (7.1\%) and a standard deviation of 7.7\%.

To examine whether executives are less likely to spend as much time in the office when the weather is particularly good, we regress quarterly GML on good_weather, as well as a combinations of year, executive role, location, and executive fixed effects. Specifications (1) through (5) in Table 10 include the full sample of 1,593 executive-quarter observations. The coefficient on good_weather varies between about -2.3 and -2.5 and is statistically significant at $1 \%$ across all five specifications, suggesting that executives shorten their work day length in quarters in which the weather is particularly favorable for outdoor activities. The coefficient indicates that a one-standard-deviation increase in good_weather in a given quarter is associated with about 10 fewer minutes per day in the office. With about 66 weekdays in a quarter, this translates to about 12 hours out of the office.

In the specifications (6), (7), and (8), we examine whether this behavior varies across executive roles. The results indicate that it is particularly strong for CEOs and CFOs, and not significant for other named executives. For a CEO and CFO, a one-standard-deviation increase in good_weather is associated with about 20 and 18 fewer hours in the officer per quarter, respectively.

\subsection{Effort and Competition}

The last consideration that we explore is how executives respond to competition in the product market place. To measure competition, we focus on the firm's growth in quarterly sales relative to its peers. The idea is that an increase in peer firm sales relative to the firm should induce more effort since executive performance is also assessed by market share. To construct a representative set of peers, for each firm, we include up to 10 closest peers (when the data allows), using the GICS6 industry classification. Closest peers are defined based on the smallest absolute difference in firm market cap. 
Our measure of growth in quarterly sales (\%Chng_Sales) is defined as the percentage change in the firm's sales during fiscal quarter $t$ relative to the firm's quarterly sales 4 quarters prior [(Sales t - Sales t-4)/Sales t-4)] in \%. In a similar manner, \%Chng_PeerSales is defined as the percentage change in the firm's peers' sales during fiscal quarter t relative to the firm's peers' quarterly sales 4 quarters prior. We then calculate the market-cap value-weighted average across all peers.

We report the results in Table 11. Following the same methodology in Table 4, we run quarterly regressions of changes in executive effort $\left(D_{-} G M L\right)$ on lagged changes in quarterly firm sales and lagged changes in quarterly peer firms' sales. As in Table 4, change in executive effort (D_GML) is defined as the difference in GML during the fiscal quarter minus the same measure during the fiscal quarter 4 quarters prior.

All specifications include executive fixed effects, thus the analysis is conducted at the executive level. In Specifications 1-3, we explore the effect of both firm growth in sales and peer growth in sales on changes during quarter $t-1$ on $G M L$ over the next quarter. Strikingly, while the firm's own growth in sales does not predict subsequent changes in GML, growth in peer firms' sales has a positive and significant effect on GML. The effect is economically significant. A 5\% increase in peer firms sales is associated with an increase of 0.40 hours during the next quarter $(0.078 \times 5=0.40)$. Note that the quarterly financial results are reported toward the end of the first month of the subsequent quarter. Thus, our estimates likely underestimate the true effect, since $G M L$ is estimated over the entire quarter period.

Controlling for firm characteristics slightly attenuates the effect of peer firms (0.06, Specification 6). Including changes in sales in quarter $t-2$ confirms that executives do respond to the changes in sales of the most recent quarter (i.e., $t-1)$. In the last two specificaitons, we exclude financial firms. The coefficient estimates are not materially different from what is reported in the other specificaitons. However, as in Table 7, the low number of observations makes the estimation noiser, which reduces statistical significance.

\section{Conclusion}

While hidden action problems are ubiquitous in firms and markets, technology is making it easier to assess hidden action problems. Indeed, the use of cookies and web traffic surveillance 
makes it easier to follow peoples' actions, even when they do not suspect it. We predict that such monitoring may eventually shed light on many unresolved issues in economics.

In this paper, we do not employ such tactics, but rely on a publicly-available measure to characterize how effort affects firm-value. While we are careful not to collect information about the nature of how actually executives use Bloomberg (for privacy reasons), we are able to conclude that higher attention to their firm and higher work intensity appear to be associated with positive earnings surprises and abnormal stock returns. This was not obvious ex ante, since it could have been the case that effort was inefficient or possibly misguided.

Finally, we consider several agency issues that have been highlighted in the academic literature. We find that executives do decrease effort when the benefit of receiving higher compensation is outside of their locus of control and when weather conditions make it attractive to engage in outside activities. In contrast, effort provision does appear to respond positively to competition within an executive's industry, measured by sales growth by competing firms. 


\section{References}

Aboody, D., Johnson, N. B., and Kasnik, R. "Employee stock options and future firm performance: Evidence from option repricings”. Journal of Accounting and Economics 50: 7492, 2010.

Bandiera, O., Hansen, S., Pratt, A., and Sadun, R. “CEO Behavior and Firm Perfomance”. Forth coming in Journal of Political Economy.

Bebchuk, L. A., and Fried, J. M. “Executive Compensation as an Agency Problem”. Journal of Economic Perspectives 17: 71-92, 2003.

Bennett, B., Bettis, J. C., Gopalan, R. and Milborn, T. “Compensation goals and firm performance”. Journal of Financial Economics 124: 307-330, 2017.

Berle, A., A. and Means, G. C. The Modern Corporation and Private Property, New York, 1932.

Bertrand, M. and Mullainathan, S. “Are CEO’s rewarded for luck? The ones without principals are”. Quarterly Journal of Economics 116(3): 901-932, 2001.

Biggerstaff, L., Ciceero, D.C., and Puckett, A. "FORE! An Analysis of CEO Shirking”. Management Science 63(7): 2302-2322, 2017.

Bröde, P., Fiala, D., Błażejczyk, K., Holmér, I., Jendritzky, G., Kampmann, B., Tinz, B., and Havenith, G. "Deriving the operational procedure for the Universal Thermal Climate Index (UTCI)." International Journal of Biometeorology 56, no. 3 (2012): 481-494.

Cogwill, B. and Zitzewitz, E. “Incentive Effects of Equity Compensation: Employee-level evidence from Google”. Working paper, Dartmouth College.

Coughlan, A. T. and Schmidt, R.M. "Executive compensation, management turnover, and firm performance”. Journal of Accounting and Economics 7: 43-66, 1985.

Core, J. and Guay, W. “The Use of Equity Grants to Manage Optimal Equity Incentive Levels”. Journal of Accounting and Economics 28: 151-84, 1999.

Core, J. and Guay, W. "Estimating the Value of Employee Stock Option Portfolios and Their Sensitivities to Price Volatility”. Journal of Accounting Research 40: 613-30, 2002.

Degeorge, F., Patel, J. and Zeckhauser, R. "Earnings management to exceed thresholds." Journal of Buriness 72(1): 1-33, 1999.

Edmans, A. and Gabaix, X. “Executive Compensation: A Modern Primer”. Journal of Economic Literature 54(4), 1232-1287, 2016. 
Edmans, A., Gabaix, X., and Jenter, D. "Executive Compensation: A Survey of Theory and Evidence”. Chapter 9 in Benjamin E. Hermalin and Michael S. Weisbach (eds.), Handbook of the Economics of Corporate Governance, Elsevier: Amsterdam, 383-539, 2017.

Foster, G., Olsen, C. and Shevlin, T. "Earnings releases, anomalies, and the behavior of security returns." Accounting Review 59(4): 574-603, 1984.

Frydman, C. and Saks, R.E. "Executive Compensation: A New View from a Long-Term Perspective, 1936-2005”. Review of Financial Studies 23(5): 2099- 2138, 2010.

Gormley, T. A., Matsa, D. A., and Milborn, T. "CEO compensation and corporate risk: Evidence from a natural experiment”. Journal of Accounting and Economics 56: 79-101, 2013.

Hall, B. J., and Liebman, J. B. “Are CEOs Really Paid Like Bureaucrats?” Quarterly Journal of Economics 113: 653-91, 1998.

Hall, B.J. and Murphy, K.J. “Stock Options for Undiversified Executives”. Journal of Accounting and Economics 33(1): 3-42, 2002.

Hayes, R.M., Lemmon, M., and Qui, M. "Stock options and managerial incentives for risktaking: Evidence from FAS 123R”. Journal of Financial Economics 105: 174-190, 2012.

Healy, P.M. “The Effect of Bonus Schemes on Accounting Decisions”. Journal of Accounting and Economics 7: 85-107, 1985.

Holmstrom, B. and Milgrom, P. “Aggregation and Linearity in the Provision of Intertemporal Beliefs”. Econometrica 55(2): 303-328, 1987.

Jensen, M. C. and Murphy, K.J. “Performance Pay and Top-Management Incentives”. Journal of Political Economy 98(2): 225-264, 1990.

Mehran, H. "Executive compensation structure, ownership, and firm performance”. Journal of Financial Economics 38: 163-184, 1995.

Mintzberg, H. The Nature of Managerial Work Harper and Row., New York, 1973.

Morck, R., Shleifer,A., and Vishny, R.W. "Management owenership and market valuation: An empirical analysis”. Journal of Financial Economics 20: 293-315, 1988.

Murphy, K. J. “Corporate Performance and Managerial Remuneration: An Empirical Analysis”. Journal of Accounting and Economics 7:11-42, 1985.

Murphy, K.J. “Executive Compensation” in Orley Ashenfelter and David Card (eds.) Handbook of Labor Economics, Vol. 3b, Elsevier Science North Holland, Chapter 38: 2485-2563, 1999. 
Murphy, K. J. "Performance Standards in Incentive Contracts," Journal of Accounting and Economics 30 (3): 245-78, 2000.

Tartarini, F., Schiavon, S., 2020. pythermalcomfort: A Python package for thermal comfort research. SoftwareX 12, 100578. https://doi.org/10.1016/j.softx.2020.100578

The Commission for Thermal Physiology of the International Union of Physiological Sciences (2003) Glossary of terms for thermal physiology. Journal of Thermal Biology 28:75-106. doi:10.1016/S0306-4565 (02)00055-4

Yermack, D. “Do corporations award CEO stock options effectively?”. Journal of Financial Economics 39: 237-269, 1995.

Yermack, D. Tailspotting: "Identifying and profiting from CEO vacation trips”. Journal of Financial Economics 113: 252-269, 2014.

Zare, S., Hasheminejad, N., Shirvan, H. E., Hemmatjo, R., Sarebanzadeh, K., and Ahmadi, S. "Comparing Universal Thermal Climate Index (UTCI) with selected thermal indices/environmental parameters during 12 months of the year." Weather and Climate Extremes 19 (2018): 49-57. 


\section{Tables and Figures:}

\section{Table 1. Summary Statistics:}

The table reports the summary statistics of firm characteristics (Panel A) of executives' firms, executives' and their industries (Panel B). Our full sample includes data 520 executive-year observations for 252 named executives online on Bloomberg with accounting data on Compustat. Size is the market capitalization of the firm's stock (measured in millions of dollars), $Q$ is Tobin's Q, Leverage is long term debt (Compustat item dltt) plus debt in current liabilities (Compustat item $\mathrm{dlc}$ ) all divided by total assets (Compustat item at). productivity is revenues (Compustat item sale) divided by total assets. Industries in Panel B are defined using the Fama French 12 industry definitions which are available on Kenneth French's website.

\section{Panel 1.A - Firm Characteristics}

\begin{tabular}{lcccccc}
\hline Variable & $\mathrm{N}$ & Mean & Std Dev & 25th Pctl & Median & 75th Pctl \\
\cline { 2 - 7 } \cline { 3 - 7 } size & 520 & 43,194 & 68,842 & 5,389 & 12,894 & 51,390 \\
$\mathrm{Q}$ & 520 & 1.588 & 1.102 & 1.018 & 1.179 & 1.755 \\
Leverage & 520 & 0.314 & 0.239 & 0.118 & 0.269 & 0.455 \\
productivity & 520 & 0.353 & 0.393 & 0.060 & 0.237 & 0.494 \\
\hline
\end{tabular}


Panel 1.B - Industries

\begin{tabular}{lccc}
\hline Industry & & N OBS & Pct of Sample \\
\cline { 3 - 4 } \cline { 3 - 3 } Finance & 284 & $54.6 \%$ \\
Other & 65 & $12.5 \%$ \\
Energy & & 48 & $9.2 \%$ \\
Utilities & 33 & $6.3 \%$ \\
Healthcare & 32 & $6.2 \%$ \\
Business Equipment & 17 & $3.3 \%$ \\
Chemicals & 10 & $1.9 \%$ \\
Consumer NonDurables & 10 & $1.9 \%$ \\
Telecommunications & 9 & $1.7 \%$ \\
Manufacturing & 8 & $1.5 \%$ \\
Wholesale and Retail & 3 & $0.6 \%$ \\
Consumer Durables & 1 & $0.2 \%$ \\
\hline
\end{tabular}




\section{Table 2. Effort Measures}

The table reports the summary statistics of terminal usage by executives as well as the derived effort measure. Our sample includes data for 252 named executives that are online on Bloomberg during sample period at firms with data in the Compustat database. Summary statistics for Bloomberg usage are presented for both "Active" and "Mobile", where Active indicates that the executive is actively using the Bloomberg terminal and Mobile indicates that the executive is actively using the Bloomberg Professional mobile application. The effort measure GML (Gaussian Mixture Length) is our measure of workday length (in hours) during the fiscal year. See Section 2.3 for details on the construction of GML. Data used in the table cover the period from September 2017 to December 2019 and effort and usage variables are measured over the fiscal year of a given executive's firm.

\begin{tabular}{|c|c|c|c|c|c|c|}
\hline \multicolumn{7}{|l|}{ Sample Coverage: } \\
\hline named executives: & 252 & & & & & \\
\hline executive-year obs: & 520 & & & & & \\
\hline mean days: & 178 & & & & & \\
\hline mean workdays (Mon-Fri): & 129 & & & & & \\
\hline mean weeks: & 31 & & & & & \\
\hline & \multicolumn{3}{|c|}{ Active } & \multicolumn{3}{|c|}{ Mobile } \\
\hline Bloomberg Usage: & Mean & Median & St Dev & Mean & Median & St Dev \\
\hline weekly & 6.92 & 5.31 & 5.81 & 0.45 & 0.15 & 0.96 \\
\hline evenings (Mon-Fri) & 0.13 & 0.06 & 0.29 & 0.05 & 0.01 & 0.11 \\
\hline weekend (per day) & 0.06 & 0.00 & 0.19 & 0.02 & 0.00 & 0.08 \\
\hline holidays & 0.54 & 0.14 & 0.86 & 0.04 & 0.00 & 0.27 \\
\hline Effort Measure: & Mean & St Dev & 25th pctl & Median & 75th Pctl & \\
\hline$\overline{G M L}$ (Gaussian Mixture Length) & 9.47 & 2.10 & 8.13 & 9.19 & 10.46 & \\
\hline
\end{tabular}




\section{Table 3. Executive Activity During Events}

The table provides statistics on executive activity on Bloomberg Terminals during investment banking conferences/presentations, analyst days, investor dayss, annual meetings, earnings releases, and earnings calls. Executives are considered "inactive" if they are not actively using the Bloomberg Terminal at any point during the 30 mintues following the beginning of the event. For the Conference/Presentation and Analyst/Investor Day events, we examine transcripts of the events on Factiva to determine whether the executive was present. For those two events, we exclude any active executives who are not listed as participants in the event. Data on event descriptions, dates, start times, and other details are collected from the Bloomberg terminal using the "EVTS" function. Data cover the fiscal years 2017 - 2019.

\begin{tabular}{|c|c|c|c|c|c|c|c|c|c|}
\hline & \multicolumn{3}{|c|}{ CEOs } & \multicolumn{3}{|c|}{ CFOs } & \multicolumn{3}{|c|}{ Other } \\
\hline & events & inactive & pct & events & inactive & pct & events & inactive & pct \\
\hline Conference/Presentation & 410 & 408 & $99.5 \%$ & 784 & 783 & $99.9 \%$ & 287 & 284 & $99.0 \%$ \\
\hline Analyst/Investor Day & 35 & 35 & $100.0 \%$ & 55 & 55 & $100.0 \%$ & 27 & 27 & $100.0 \%$ \\
\hline Annual Meeting & 70 & 66 & $94.3 \%$ & 122 & 111 & $91.0 \%$ & 67 & 61 & $91.0 \%$ \\
\hline Earnings Release & 327 & 244 & $74.6 \%$ & 543 & 393 & $72.4 \%$ & 316 & 257 & $81.3 \%$ \\
\hline Earnings Call & 312 & 271 & $86.9 \%$ & 544 & 486 & $89.3 \%$ & 303 & 263 & $86.8 \%$ \\
\hline
\end{tabular}




\section{Table 4. Effort and Earnings Surprise}

The table provides results of regressions of earnings surprises on changes in CEO and CFO effort, measures of insider trading, and firm characteristics. The measure of earnings surprise is Standardized Unexpected Earnings (SUE), which is defined as the difference in the current quarterly earnings per share and the earnings per share 4 quarters prior divided by the standard deviation of these differences measured over the previous eight quarters. Change in effort ( $\left.D \_G M L\right)$ is defined as the difference in $G M L$ during the fiscal quarter minus the same measure during the fiscal quarter 4 quarters prior. The first 7 specifications include executives in all industires while specification 9 is limited to those in non-financial firms. Four measures of insider trading are included in the regressions based on differences in insider trading between the fiscal quarter and the fiscal quarter 4 quarter prior. The variables $D \_p u r c h a s e$, and $D \_s e l l$, are the differences in log dollar amount of open market insider purchases and sales, respectively, by the executive during the fiscal quarter associated with the earnings announcement minus the amounts 4 quarters prior. The variables $D \_p u r c h a s e \_a l l$ and $D \_s e l l \_a l l$ are the log dollar amount of open market insider purchases and sales by all insiders at the firm during the fiscal quarter minus the amounts 4 quarters prior. Insider trading data are from the SEC Edgar database. Terminal activity are from Bloomberg, analyst forecast and earnings per share data are from I/B/E/S, and Fama-French 12 industry definitions are from Ken French's website. Firm characteristics, size, leverage, productivity, and Tobin's Q are from CRSP and Compustat and are included where indicated. An intercept is estimated in each regression, but not reported. Standard errors are clustered by executive and are reported in parentheses. Statistical significance at the $10 \%, 5 \%$, and $1 \%$ level is indicated with $*{ }^{* *}$, and ${ }^{* * *}$, respectively.

\begin{tabular}{|c|c|c|c|c|c|c|c|c|c|}
\hline Variable & $(1)$ & (2) & (3) & $(4)$ & (5) & (6) & (7) & (8) & (9) \\
\hline$D_{-} G M L$ & $\begin{array}{c}0.063 \\
(0.027) * *\end{array}$ & $\begin{array}{c}0.058 \\
(0.026)\end{array}$ ** & $\begin{array}{c}0.078 \\
(0.025) * * *\end{array}$ & $\begin{array}{c}0.075 \\
(0.024)\end{array} * * *$ & $\begin{array}{c}0.062 \\
(0.026)\end{array}$ ** & $\begin{array}{c}0.054 \\
(0.025)\end{array}$ ** & $\begin{array}{c}0.062 \\
(0.026)\end{array}$ ** & $\begin{array}{c}0.053 \\
(0.025)\end{array}$ ** & $\begin{array}{c}0.077 \\
(0.035)\end{array}$ \\
\hline D_purchase & $\begin{array}{l}-0.008 \\
(0.054)\end{array}$ & $\begin{array}{r}0.022 \\
(0.051)\end{array}$ & $\begin{array}{l}-0.015 \\
(0.055)\end{array}$ & $\begin{array}{r}0.016 \\
(0.052)\end{array}$ & $\begin{array}{r}-0.018 \\
(0.051)\end{array}$ & $\begin{array}{r}0.008 \\
(0.047)\end{array}$ & $\begin{array}{c}-0.018 \\
(0.051)\end{array}$ & $\begin{array}{r}0.008 \\
(0.047)\end{array}$ & $\begin{array}{l}-0.106 \\
(0.030) * * *\end{array}$ \\
\hline D_sell & $\begin{array}{l}-0.011 \\
(0.014)\end{array}$ & $\begin{array}{r}-0.001 \\
(0.013)\end{array}$ & $\begin{array}{r}-0.009 \\
(0.012)\end{array}$ & $\begin{array}{l}-0.001 \\
(0.011)\end{array}$ & $\begin{array}{l}-0.015 \\
(0.011)\end{array}$ & $\begin{array}{r}-0.003 \\
(0.010)\end{array}$ & $\begin{array}{l}-0.015 \\
(0.011)\end{array}$ & $\begin{array}{r}-0.003 \\
(0.010)\end{array}$ & $\begin{array}{r}0.002 \\
(0.020)\end{array}$ \\
\hline D_purchase_all & & $\begin{array}{c}-0.030 \\
(0.012) * *\end{array}$ & & $\begin{array}{c}-0.031 \\
(0.012)\end{array}$ ** & & $\begin{array}{c}-0.027 \\
(0.013) * *\end{array}$ & & $\begin{array}{c}-0.027 \\
(0.013)\end{array}$ ** & $\begin{array}{l}-0.049 \\
(0.020)\end{array}$ ** \\
\hline D_sell_all & & $\begin{array}{l}-0.011 \\
(0.008)\end{array}$ & & $\begin{array}{l}-0.007 \\
(0.009)\end{array}$ & & $\begin{array}{c}-0.015 \\
(0.009)\end{array}$ & & $\begin{array}{c}-0.015 \\
(0.009)\end{array}$ & $\begin{array}{c}-0.028 \\
(0.015)\end{array}$ \\
\hline Non-Fin Firms Only? & NO & NO & NO & NO & NO & NO & NO & YES & YES \\
\hline Firm Controls? & NO & NO & YES & YES & YES & YES & YES & YES & YES \\
\hline Industry FE? & NO & NO & NO & NO & YES & YES & YES & YES & YES \\
\hline Executive Role FE? & NO & NO & NO & NO & NO & NO & YES & YES & YES \\
\hline$N O B S$ & 436 & 436 & 436 & 436 & 436 & 436 & 436 & 436 & 187 \\
\hline R-Squared & 0.010 & 0.026 & 0.100 & 0.115 & 0.166 & 0.184 & 0.166 & 0.184 & 0.287 \\
\hline
\end{tabular}




\section{Table 5. Effort and Earnings Announcement Returns}

The table provides results of regressing cumulative abnormal stock returns (in basis points) around earnings announcements on executive effort measured during the fiscal quarter associated with the earnings as well as standardized unexpected earnings (SUE), and measures of insider trading during the fiscal quarter. Panel A provides results for all executives. Panel B provides results for executives at non-financial firms. Each reported coefficient represents a single regression using GML. Cumulative returns are measured using the Fama-French 3 Factor model where factor loadings are estimated using a year of past daily stock returns (skipping the most recent week). Cumulative abnormal returns are presented for ranges of 1 through 50 trading days where the first day is the trading day that includes the announcement. Terminal activity are from Bloomberg and stock price data are from CRSP. Fama French factor portfolios are from Ken French's website. SUE is defined as the difference in the current quarterly earnings per share and the earnings per share 4 quarters prior divided by the standard deviation of these differences measured over the previous eight quarters. Four measures of insider trading are included in the regressions. The variables $\log _{\text {p }}$ urchase, and $\log _{\text {_ }}$ sell, are the log dollar amount of open market insider purchases and sales, respectively, by the executive during the fiscal quarter associated with the earnings announcement. The variables log_purchase_all and log_sell_all are the log dollar amount of open market insider purchases and sales by all insiders at the firm during the fiscal quarter. Insider trading data are from the SEC Edgar database. To be included in the sample, an executive must have been active on Bloomberg for at least four fiscal quarters. 1,128 observations are included in the regressions. All regressions include

individual executive fixed effects. Standard errors, clustered by executive, are reported in parentheses. Statistical significance at the $10 \%, 5 \%$, and $1 \%$ level is indicated with *, **, and $* * *$, respectively. 
Panel 5.A - All Executives

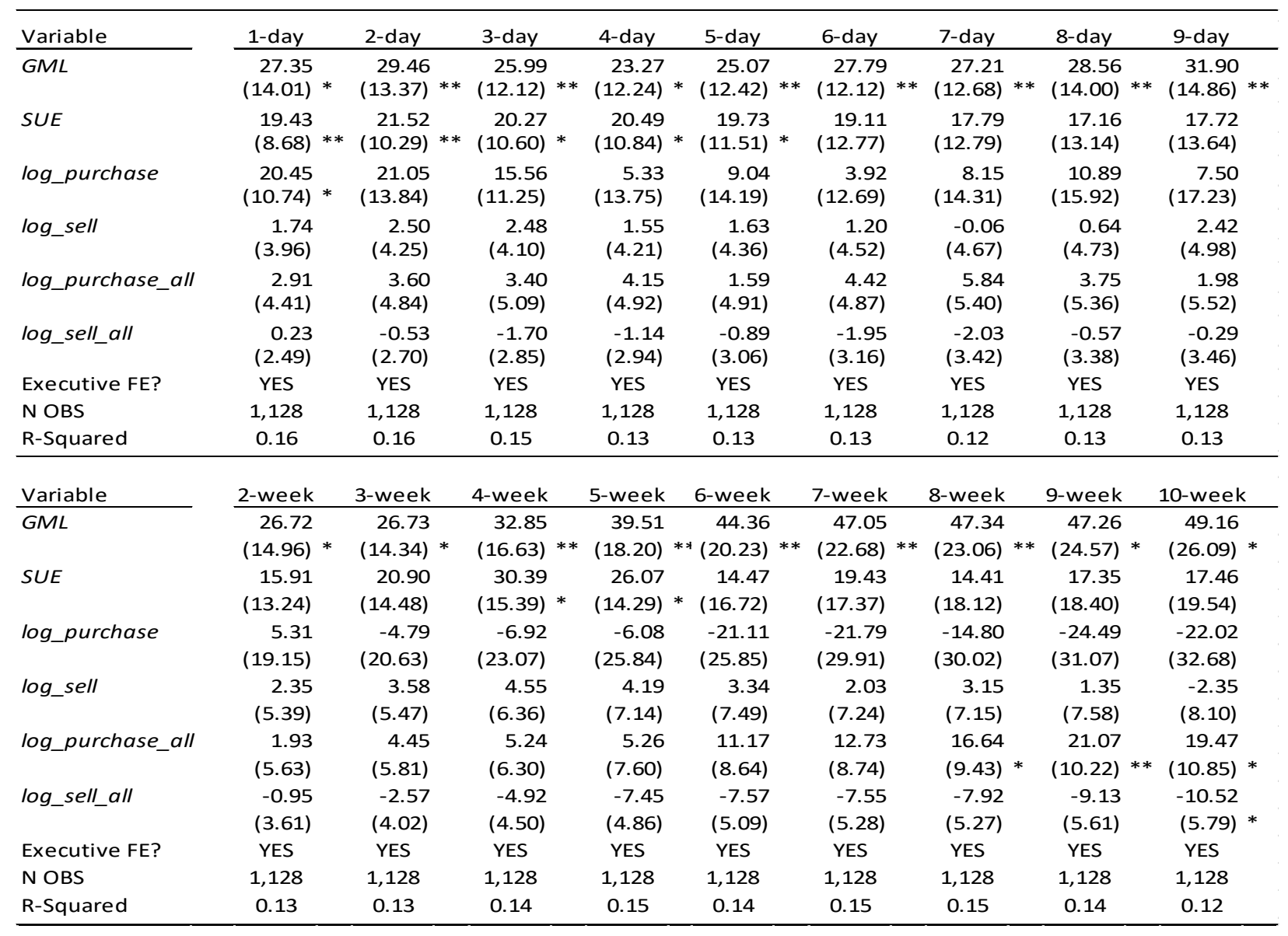


Panel 5.B - Executives at Non-Financial Firms

\begin{tabular}{|c|c|c|c|c|c|c|c|c|c|c|}
\hline Variable & 1-day & 2-day & 3-day & 4-day & 5-day & 6-day & & 7-day & 8-day & 9-day \\
\hline \multirow[t]{2}{*}{$G M L$} & 43.91 & 43.19 & 33.64 & 33.91 & 33.61 & 35.18 & & 35.33 & 42.05 & 49.16 \\
\hline & $(19.33) *$ & $(21.67) *$ & $(18.07)^{*}$ & $(15.26) *$ & $(15.57) *$ & (15.77) & $*$ & $(16.61) *$ & $(20.88) *$ & $(24.13) *$ \\
\hline \multirow[t]{2}{*}{ SUE } & 34.64 & 41.87 & 44.85 & 45.59 & 47.96 & 49.14 & & 44.28 & 42.16 & 39.93 \\
\hline & $(17.02) *$ & $(25.21)$ & (28.07) & $(27.63)$ & $(27.56)$ & $(28.71)$ & & $(28.60)$ & $(25.68)$ & $(27.94)$ \\
\hline \multirow[t]{2}{*}{ log_purchase } & 25.34 & 11.49 & 15.82 & -1.15 & 4.13 & -2.29 & & 1.77 & 6.05 & -3.70 \\
\hline & $(6.12) * * *$ & (11.34) & (8.93) & $(14.48)$ & (10.95) & (18.59) & & (16.59) & (18.80) & $(24.51)$ \\
\hline \multirow[t]{2}{*}{ log_sell } & 1.18 & 2.96 & 1.74 & 0.56 & 2.29 & 3.51 & & 3.25 & 2.85 & 6.36 \\
\hline & (6.26) & (6.35) & (6.29) & (7.63) & (7.29) & (6.42) & & (6.63) & (6.51) & (6.10) \\
\hline \multirow[t]{2}{*}{ log_purchase_all } & 3.32 & 5.25 & 5.27 & 7.78 & 2.63 & 6.71 & & 7.17 & 5.54 & 3.52 \\
\hline & (10.28) & (9.98) & (11.06) & (10.73) & (10.23) & (9.56) & & (11.32) & $(10.42)$ & (10.37) \\
\hline \multirow[t]{2}{*}{ log_sell_all } & -2.42 & -3.71 & -5.98 & -6.16 & -6.03 & -8.08 & & -8.83 & -6.30 & -5.98 \\
\hline & (5.13) & (4.68) & (6.10) & (6.19) & (5.53) & (4.99) & & $(6.47)$ & (5.07) & $(4.82)$ \\
\hline Executive FE? & YES & YES & YES & YES & YES & YES & & YES & YES & YES \\
\hline N OBS & 457 & 457 & 457 & 457 & 457 & 457 & & 457 & 457 & 457 \\
\hline R-Squared & 0.196 & 0.19 & 0.175 & 0.15 & 0.15 & 0.15 & & 0.14 & 0.14 & 0.14 \\
\hline Variable & 2-week & 3-week & 4-week & 5-week & 6-week & 7-week & & 8-week & 9-week & 10-week \\
\hline \multirow[t]{2}{*}{ GML } & 39.16 & 42.05 & 58.50 & 69.11 & 88.63 & 95.07 & & 91.33 & 96.37 & 104.38 \\
\hline & $(22.00)$ & $(20.94) *$ & $(29.94) *$ & $(29.49) * *$ & $(28.90) * *$ & $(26.85)$ & $* * *$ & $(27.33) * *$ & $(26.83) * * *$ & $(26.61) * * *$ \\
\hline \multirow[t]{2}{*}{ SUE } & 39.69 & 42.64 & 50.16 & 49.77 & 24.43 & 35.23 & & 9.51 & 14.76 & 11.47 \\
\hline & $(29.89)$ & $(37.26)$ & $(30.21)$ & $(29.56)$ & $(28.83)$ & $(27.83)$ & & (33.68) & $(67.41)$ & (75.52) \\
\hline \multirow[t]{2}{*}{ log_purchase } & -12.69 & -29.57 & -44.45 & -57.07 & -66.04 & -80.73 & & -72.36 & -81.99 & -90.72 \\
\hline & (32.33) & $(35.57)$ & (37.47) & (43.39) & (50.01) & $(61.47)$ & & $(50.40)$ & (56.71) & (61.07) \\
\hline \multirow[t]{2}{*}{ log_sell } & 6.34 & 2.10 & 3.63 & 0.85 & 0.58 & -1.97 & & 0.42 & -0.94 & -7.32 \\
\hline & $(5.81)$ & (4.96) & (6.20) & (5.18) & (5.08) & (4.64) & & (6.15) & $(4.66)$ & (8.17) \\
\hline \multirow[t]{2}{*}{ log_purchase_all } & 4.53 & 1.58 & 1.39 & 1.66 & 5.62 & 8.08 & & 13.07 & 26.26 & 19.93 \\
\hline & (9.09) & $(9.62)$ & $(7.82)$ & (8.29) & $(10.10)$ & (7.69) & & $(10.24)$ & (16.78) & $(14.85)$ \\
\hline \multirow[t]{2}{*}{ log_sell_all } & -6.73 & -8.84 & -14.09 & -16.00 & -18.07 & -20.43 & & -21.77 & -22.44 & -22.74 \\
\hline & (3.85) & $(4.44) *$ & $(5.35) * *$ & $(3.59) * * *$ & $(4.11) * * *$ & (5.65) & $* * *$ & $(6.56) * *$ & $(6.43) * * *$ & $(6.67) * * *$ \\
\hline Executive FE? & YES & YES & YES & YES & YES & YES & & YES & YES & YES \\
\hline N OBS & 457 & 457 & 457 & 457 & 457 & 457 & & 457 & 457 & 457 \\
\hline R-Squared & 0.14 & 0.13 & 0.15 & 0.18 & 0.16 & 0.18 & & 0.17 & 0.17 & 0.14 \\
\hline
\end{tabular}




\section{Table 6. Calendar Time Portfolio Returns}

The table reports mean returns of calendar time portfolios around earnings announcements based on changes in executive effort during the fiscal quarter relative to the fiscal quarter one-year prior, where effort is defined using GML. We report results for two portfolios, High_Effort and Low_Effort, as well as a portfolio that is long High Effort and short Low Effort. To be included in the High Effort portfolio on a given day, we require the change in $G M L$ for the stock's executive to be in the top $10 \%$ for all executives in the sample with the same fiscal quarter end, and the earnings announcement corresponding to the fiscal quarter must have occurred within the past five trading days. The Low Effort portfolio is defined analogously, with change in GML in the bottom 10\%. The High minus Low portfolio is the return of the High Effort portfolio minus the return of the Low Effort Portfolio. Portfolio returns are value-weighted using market capitalization weights. To reduce noise, if the number of stocks on any given day in a portfolio drops below 2, we replace the portfolio return with the risk free rate. Both raw returns and risk adjusted returns are presented in basis points. The Fama-French 3-factor model is used to adjust for risk. Factor loadings are estimated using a year of past daily stock returns (skipping the most recent week). Terminal activity are from Bloomberg and stock price data are from CRSP. Fama French factor portfolios are from Ken French's website. Newey-West standard errors using 5 lags are reported in parentheses. Statistical significance at the $10 \%, 5 \%$, and $1 \%$ level is indicated with *, **, and ***, respectively.

\begin{tabular}{|c|c|}
\hline Portfolio & $\begin{array}{l}\text { Mean } \\
\text { (bps) }\end{array}$ \\
\hline \multicolumn{2}{|l|}{ Raw Return } \\
\hline High_Effort & $\begin{array}{c}4.678 \\
(2.498) *\end{array}$ \\
\hline Low_Effort & $\begin{array}{l}-2.520 \\
(2.822)\end{array}$ \\
\hline High minus Low & $\begin{array}{c}7.198 \\
(3.686) *\end{array}$ \\
\hline \multicolumn{2}{|l|}{ Risk-Adjusted Return } \\
\hline High_Effort & $\begin{array}{l}4.579 \\
(1.569) * * *\end{array}$ \\
\hline Low_Effort & $\begin{array}{l}-2.751 \\
(2.355)\end{array}$ \\
\hline High minus Low & $\begin{array}{l}7.330 \\
(3.129) * * *\end{array}$ \\
\hline
\end{tabular}




\section{Table 7. Effort and Credit Default Swap Spreads}

The table provides results of regressions of firm CDS spreads in quarter $t+1$ on executive effort (GML) in quarter $t$, the firm's CDS spread (Spread) in quarter $t$, measures of insider trading in quarter $t$, and other firm characteristics. Daily data of 5-year CDS spreads are obtained from DataStream. For each firm and quarter, we keep the last trading day in that quarter. We keep firms with active CDS contracts during our sample period and end up with 574 observations over 89 executives and 57 firms. Due to the persistence in CDS spreads, we control for lagged Spread (i.e., an AR1 model). However, using first difference (Spread $t+1-$ Spread $t$ ) virtually provides the same results. To reduce the effect of outliers, we trim observations where the quarterly changes in spread are at the top and bottom $1 \%$ of their distribution. We include four measures of insider trading include Purchase (Sell), which is the log dollar amount of open market insider purchases (sales) by the executive during quarter q, and Purchase_All (Sell_All), which is the log dollar amount of open market insider purchases (sales) by all insiders during quarter $q$. Insider trading data are from the SEC Edgar database. Terminal activity are from Bloomberg, analyst forecast and earnings per share data are from I/B/E/S, and Fama-French 12 industry definitions are from Ken French's website. Firm characteristics, size, sales, leverage, productivity, and Tobin's $\mathrm{Q}$ are from CRSP and Compustat and are included where indicated. An intercept is estimated in each regression, but not reported. All specifications include year fixed effects. Standard errors are clustered by executive and are reported in parentheses. Statistical significance at the $10 \%, 5 \%$, and $1 \%$ level is indicated with *, **, and ***, respectively.

\begin{tabular}{|c|c|c|c|c|c|c|c|c|c|}
\hline Variable & (1) & $(2)$ & (3) & (4) & (5) & (6) & (7) & (8) & (9) \\
\hline$G M L$ & $\begin{array}{l}-0.791 \\
(0.320) * *\end{array}$ & $\begin{array}{l}-0.879 \\
(0.330) * * *\end{array}$ & $\begin{array}{l}-0.929 \\
(0.380) * *\end{array}$ & $\begin{array}{l}-0.976 \\
(0.390) * *\end{array}$ & $\begin{array}{l}-1.504 \\
(0.600) * *\end{array}$ & $\begin{array}{l}-1.486 \\
(0.600) * *\end{array}$ & $\begin{array}{l}-1.410 \\
(0.590) * *\end{array}$ & $\begin{array}{r}-0.964 \\
(0.720)\end{array}$ & $\begin{array}{l}-1.113 \\
(0.690)\end{array}$ \\
\hline Spread & $\begin{array}{c}0.996 \\
(0.040) * * *\end{array}$ & $\begin{array}{c}0.995 \\
(0.040) * * *\end{array}$ & $\begin{array}{c}0.998 \\
(0.040) * * *\end{array}$ & $\begin{array}{c}0.994 \\
(0.040) * * *\end{array}$ & $\begin{array}{c}0.700 \\
(0.150) * * *\end{array}$ & $\begin{array}{c}0.700 \\
(0.150) * * *\end{array}$ & $\begin{array}{c}0.704 \\
(0.150)\end{array} * * *$ & $\begin{array}{c}0.672 \\
(0.194)\end{array} * * *$ & $\begin{array}{c}0.591 \\
(0.185)\end{array} * * *$ \\
\hline log_Purchase & & & & & & $\begin{array}{l}-0.277 \\
(0.730)\end{array}$ & & & \\
\hline Log_Sell & & & & & & $\begin{array}{l}-0.104 \\
(0.100)\end{array}$ & & & \\
\hline Log_Purchase_all & & & & & & & $\begin{array}{r}-0.269 \\
(0.240)\end{array}$ & & \\
\hline Log_Sell_All & & & & & & & $\begin{array}{l}-0.097 \\
(0.130)\end{array}$ & & \\
\hline Firm Controls? & NO & NO & NO & YES & YES & YES & YES & NO & YES \\
\hline Industry FE? & NO & NO & YES & YES & YES & YES & YES & YES & YES \\
\hline Executive FE? & NO & NO & NO & NO & YES & YES & YES & YES & YES \\
\hline Excluding Financials? & NO & NO & NO & NO & NO & NO & NO & YES & YES \\
\hline$N O B S$ & 574 & 574 & 574 & 574 & 574 & 574 & 574 & 260 & 260 \\
\hline$R$-Squared & 0.924 & 0.924 & 0.923 & 0.925 & 0.928 & 0.928 & 0.928 & 0.940 & 0.943 \\
\hline
\end{tabular}




\section{Table 8. Ex-Ante Incentive Contracts}

The table reports the summary statistics of the excutives' compensation and targets. This sample consists of 252 executives with compensation data in ISS Incentive Lab. value_stock_owned is the dollar value of the executive's stockholdings in the firm. salary is the executives' fixed salary during the fiscal year. cash_perf is the target dollar amount of the cash-based performance incentive bonus from the executive's compensation contract for the fiscal year. stock_perf is the target dollar amount of the stock-based performance incentive bonus from the contract. stock_time and option_time are the values of the time-based stock and option grants, respectively, from the contract. Predicted compensation, pred_comp, is the sum of salary, cash_perf, stock_perf, stock_time, and option_time. The cash performance metric types Accounting, Individual, Stock Price, and Other are the weights of the categories for the metrics that determine the executive's cash based incentive program. Metrics are categorized by incentive lab and the weights of each metric are collected from the proxy statements.

\begin{tabular}{|c|c|c|c|c|c|c|}
\hline Variable & $\mathrm{N}$ & Mean & Std Dev & 25th Pctl & Median & 75th Pctl \\
\hline \multicolumn{7}{|l|}{ Executive Role } \\
\hline CEO & 520 & $27 \%$ & & & & \\
\hline CFO & 520 & $45 \%$ & & & & \\
\hline \multicolumn{7}{|l|}{ Compensation Contracts } \\
\hline value_stock_owned & 520 & 68,952 & 239,370 & 3,081 & 10,693 & 38,826 \\
\hline pct firm_owned & 520 & $0.77 \%$ & $3.81 \%$ & $0.02 \%$ & $0.07 \%$ & $0.21 \%$ \\
\hline pred_comp & 520 & 7,227 & 14,706 & 2,203 & 4,178 & 7,696 \\
\hline salary & 520 & 783 & 452 & 500 & 675 & 1,000 \\
\hline cash_perf & 520 & 1,180 & 1,944 & 138 & 643 & 1,350 \\
\hline stock_perf & 520 & 2,530 & 3,963 & 360 & 1,239 & 3,016 \\
\hline stock_time & 520 & 2,154 & 12,269 & 0 & 345 & 1,295 \\
\hline option_time & 520 & 566 & 1,304 & 0 & 0 & 497 \\
\hline \multicolumn{7}{|c|}{ Cash Performance Metric Types } \\
\hline Accounting & 520 & $62.79 \%$ & & & & \\
\hline Other & 520 & $27.60 \%$ & & & & \\
\hline Individual & 520 & $7.08 \%$ & & & & \\
\hline Stock Price & 520 & $2.53 \%$ & & & & \\
\hline
\end{tabular}




\section{Table 9. Incentive Contracts and Effort - Earnings Targets}

The table provides results of regressions of changes in GML between the $1^{\text {st }}$ half of the fiscal year and the $2^{\text {nd }}$ half of the fiscal year on a target_1_pct, which indicates that earnings per share in the $1^{\text {st }}$ half of the fiscal year are on an annualized pace to finish within $1 \%$ of the annual target in the executive's cash bonus compensation contract, on the variable pct_cash_perf, and on an interaction between the two variables. target_1_pct is equal to 1 if the quantity $\mid 2 *\left(E P S_{Q 1}+E P S_{Q 2}\right)-E P S$ Target|/EPS Target is less than $1 \%$, where $Q 1$ and Q2 indicate the first two fiscal quarters of the year and EPS Target is the EPS target in the executive's bonus contract. Additional control variables include the logarithm of predicted compensation, log_pred_comp, the logarithm of the value of shares of the firm's stock owned by the executive, and the firm characteristics leverage, size, productivity, and Tobin's Q, as well as executive role fixed effects, industry fixed effects, and fiscal year fixed effects, where indicated. The final specification includes GML (measured over the entire fiscal year) as a dependent variable. The prefixes $\log$ on the compensation variable indicates a natural logarithm of the variable while the prefix pct indicates that the variable has been scaled by predicted compensation, pred_comp.CEO and CFO fixed effects indicate whether the executive's role is that of the Chief Executive Officer or Chief Financial Officer, respectively. Terminal activity data are from Bloomberg. Target bonus award amounts and other compensation data are from ISS Incentive Lab and variables are defined in Table 2. Twelve Fama French Industry Fixed Effects and Fiscal Year fixed effects are included. Data from 55 executives with profile activity data on Bloomberg for at least one quarter in the first half of a fiscal year and one quarter in the second half are included in the regressions. Standard errors are clustered by executive and are reported in parentheses. Statistical significance at the $10 \%, 5 \%$, and $1 \%$ level is indicated with *, **, and $* * *$, respectively. 


\begin{tabular}{|c|c|c|c|c|}
\hline \multirow[b]{2}{*}{ Variable } & \multicolumn{3}{|c|}{ GML CHANGE } & \multirow{2}{*}{$\frac{G M L}{(4)}$} \\
\hline & (1) & $(2)$ & (3) & \\
\hline pct_cash_perf*target_1_pct & $\begin{array}{l}21.068 \\
(7.251)^{* *}\end{array}$ & $\begin{array}{c}22.724 \\
(7.715) * *\end{array}$ & $\begin{array}{c}19.669 \\
(7.769) * *\end{array}$ & \\
\hline target_1_pct & $\begin{array}{l}-5.193 \\
(1.949) * *\end{array}$ & $\begin{array}{l}-5.495 \\
(2.141) * *\end{array}$ & $\begin{array}{c}-4.575 \\
(2.257) * *\end{array}$ & \\
\hline log_pred_comp & $\begin{array}{r}0.471 \\
(0.417)\end{array}$ & $\begin{array}{c}0.822 \\
(0.449) *\end{array}$ & $\begin{array}{r}0.739 \\
(0.581)\end{array}$ & $\begin{array}{r}-0.129 \\
(0.483)\end{array}$ \\
\hline pct_cash_perf & $\begin{array}{r}-1.617 \\
(2.253)\end{array}$ & $\begin{array}{r}-1.911 \\
(2.262)\end{array}$ & $\begin{array}{r}-1.378 \\
(2.153)\end{array}$ & $\begin{array}{c}2.720 \\
(1.470) *\end{array}$ \\
\hline log_shares_owned & $\begin{array}{r}-0.033 \\
(0.236)\end{array}$ & $\begin{array}{r}-0.061 \\
(0.271)\end{array}$ & $\begin{array}{r}-0.076 \\
(0.281)\end{array}$ & $\begin{array}{r}-0.057 \\
(0.192)\end{array}$ \\
\hline Firm Characteristics & YES & YES & YES & YES \\
\hline Executive Role FE? & NO & YES & YES & YES \\
\hline Industry FE? & NO & NO & YES & YES \\
\hline Fiscal Year FE? & NO & NO & YES & YES \\
\hline N OBS & 91 & 91 & 91 & 91 \\
\hline R-Square & 0.13 & 0.17 & 0.25 & 0.39 \\
\hline
\end{tabular}




\section{Table 10. Effort and Leisure}

The table provides results of regressions of changes quarterly $G M L$ on the variable good_weather, as well as various fixed effects. The effort measure GML (Gaussian Mixture Length) is a measure of workday length (in hours) during the fiscal year. See Section 2.3 for details on the construction of GML. The variable good_weather is the percentage of hours during the fiscal quarter in the executive's work location in which (a) the Universal Thermal Climate Index (UTCI) is in the "thermal comfort zone", (b) there is no precipitation, (c) the sky is not overcast, and (d) it is a daylight hour. Year fixed effects, Executive Role fixed effects (CEO, CFO, or other), location fixed effects, and executive fixed effects are included where indicated. Specifications (1) through (5) include regressions across the full sample of executives. Specifications (6), (7), and (8) are the subsamples of CEOs, CFOs, and other executives, respectively. Terminal activity data are from Bloomberg. Data from 1596 executive-quarter observations are included. Standard errors are reported in parentheses. Statistical significance at the $10 \%, 5 \%$, and $1 \%$ level is indicated with $*$, $* *$ and $* * *$, respectively.

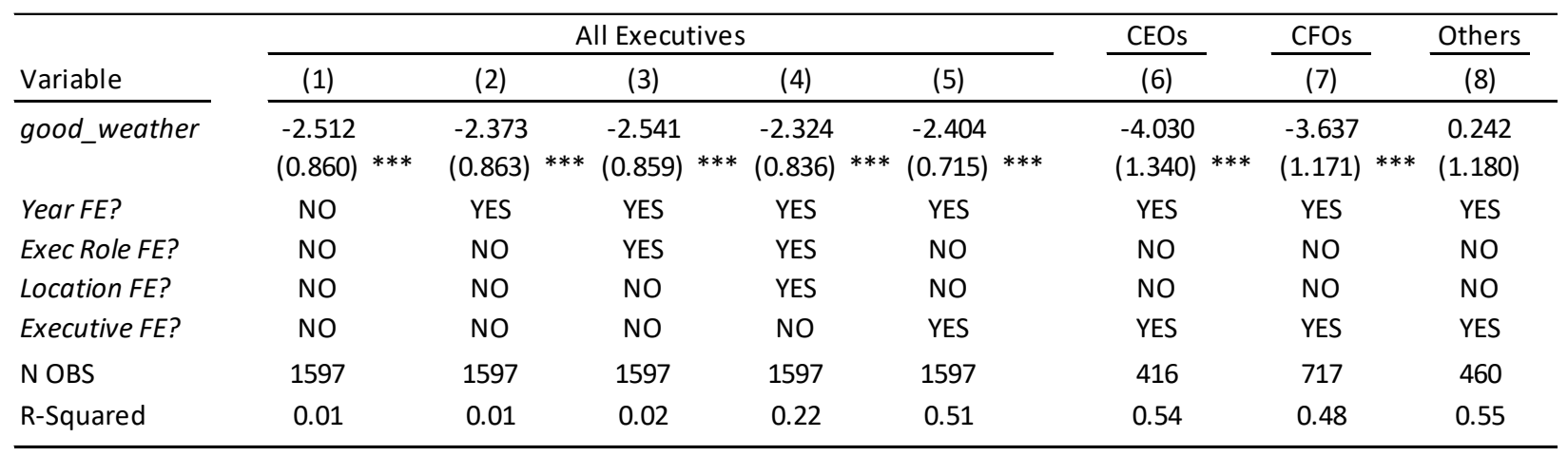




\section{Table 11. Effort and Industry Competition}

The table provides results of quarterly regressions of changes in executive effort ( $\left.D \_G M L\right)$ on lagged changes in quarterly firm sales and lagged changes in quarterly peer firms' sales. Change in effort (D_GML) is defined as the difference in $G M L$ during the fiscal quarter minus the same measure during the fiscal quarter 4 quarters prior. \%Chng_Sales is defined as the percentage change in the firm's sales during fiscal quarter $t$ relative to the firm's quarterly sales 4 quarters prior [(Sales t - Sales t-4)/Sales t-4)] in \%. In the table, Lag1 (Lag2) means the $\%$ Chng_Sales in quarter $t-1$ ( $t$-2). In a similar manner, \%Chng_PeerSales is defined as the percentage change in the firm's peers' sales during fiscal quarter $t$ relative to the firm's peers' quarterly sales 4 quarters prior. For each firm, include up to 10 closest peers based on the GICS6 industry classification, where closest peers are defined based on the smallest absolute difference in firm market cap. To aggregate the peer information, we calculate the market-cap value-weighted average across all peers. To reduce the effect of outliers, we trim $\%$ Chng_Sales and \%Chng_PeerSales at the top and bottom 1\% of their distribution. Terminal activity are from Bloomberg, analyst forecast and earnings per share data are from I/B/E/S, and Fama-French 12 industry definitions are from Ken French's website. Firm characteristics, size, leverage, productivity, and Tobin's Q are from CRSP and Compustat and are included where indicated. An intercept is estimated in each regression, but not reported. All specifications include year fixed effects. Standard errors are clustered by executive and are reported in parentheses. Statistical significance at the $10 \%, 5 \%$, and $1 \%$ level is indicated with *, **, and ***, respectively.

\begin{tabular}{|c|c|c|c|c|c|c|c|c|c|}
\hline Variable & (1) & (2) & (3) & (4) & (5) & (6) & (7) & (8) & (9) \\
\hline Lag1_\%Chng_Sales & 0.003 & & $\begin{array}{r}-0.006 \\
(0.017)\end{array}$ & $\begin{array}{c}-0.003 \\
(0.016)\end{array}$ & & $\begin{array}{r}-0.008 \\
(0.016)\end{array}$ & $\begin{array}{r}-0.015 \\
(0.019)\end{array}$ & $\begin{array}{l}-0.026 \\
(0.042)\end{array}$ & $\begin{array}{l}-0.023 \\
(0.034)\end{array}$ \\
\hline Lag1_\%Chng_PeerSales & & $\begin{array}{c}0.075 \\
(0.030)\end{array}$ ** & $\begin{array}{c}0.078 \text { * } \\
(0.034)\end{array}$ & & $\begin{array}{c}0.057 \\
(0.025) * *\end{array}$ & $\begin{array}{c}0.060 \\
(0.027) * *\end{array}$ & $\begin{array}{c}0.054 \\
(0.026)\end{array}$ ** & $\begin{array}{r}0.081 \\
(0.053)\end{array}$ & $\begin{array}{r}0.040 \\
(0.048)\end{array}$ \\
\hline Lag2_\%Chng_Sales & & & & & & & $\begin{array}{r}-0.016 \\
(0.013)\end{array}$ & & \\
\hline Lag2_\%Chng_PeerSales & & & & & & & $\begin{array}{r}0.029 \\
(0.027)\end{array}$ & & \\
\hline Firm Controls? & NO & NO & NO & YES & YES & YES & YES & NO & YES \\
\hline Industry FE? & YES & YES & YES & YES & YES & YES & YES & YES & YES \\
\hline Executive FE? & YES & YES & YES & YES & YES & YES & YES & YES & YES \\
\hline Excluding Financials? & NO & NO & NO & NO & NO & NO & NO & YES & YES \\
\hline NOBS & 506 & 506 & 506 & 506 & 506 & 506 & 493 & 180 & 180 \\
\hline$R$-Squared & 0.063 & 0.082 & 0.080 & 0.077 & 0.086 & 0.084 & 0.092 & 0.138 & 0.170 \\
\hline
\end{tabular}




\section{Figure 1. Bloomberg Screenshot}

The figure provides a screenshot for Michael Bloomberg that was obtained using the profile search on the Bloomberg terminal. The green dot by Michael Bloomberg's name indicates that he is online. Other possible status indicators are a red dot (offline), a yellow dot (idle), a gray dot (private, opted out), and a mobile phone icon indicates (user is on the mobile Bloomberg app).

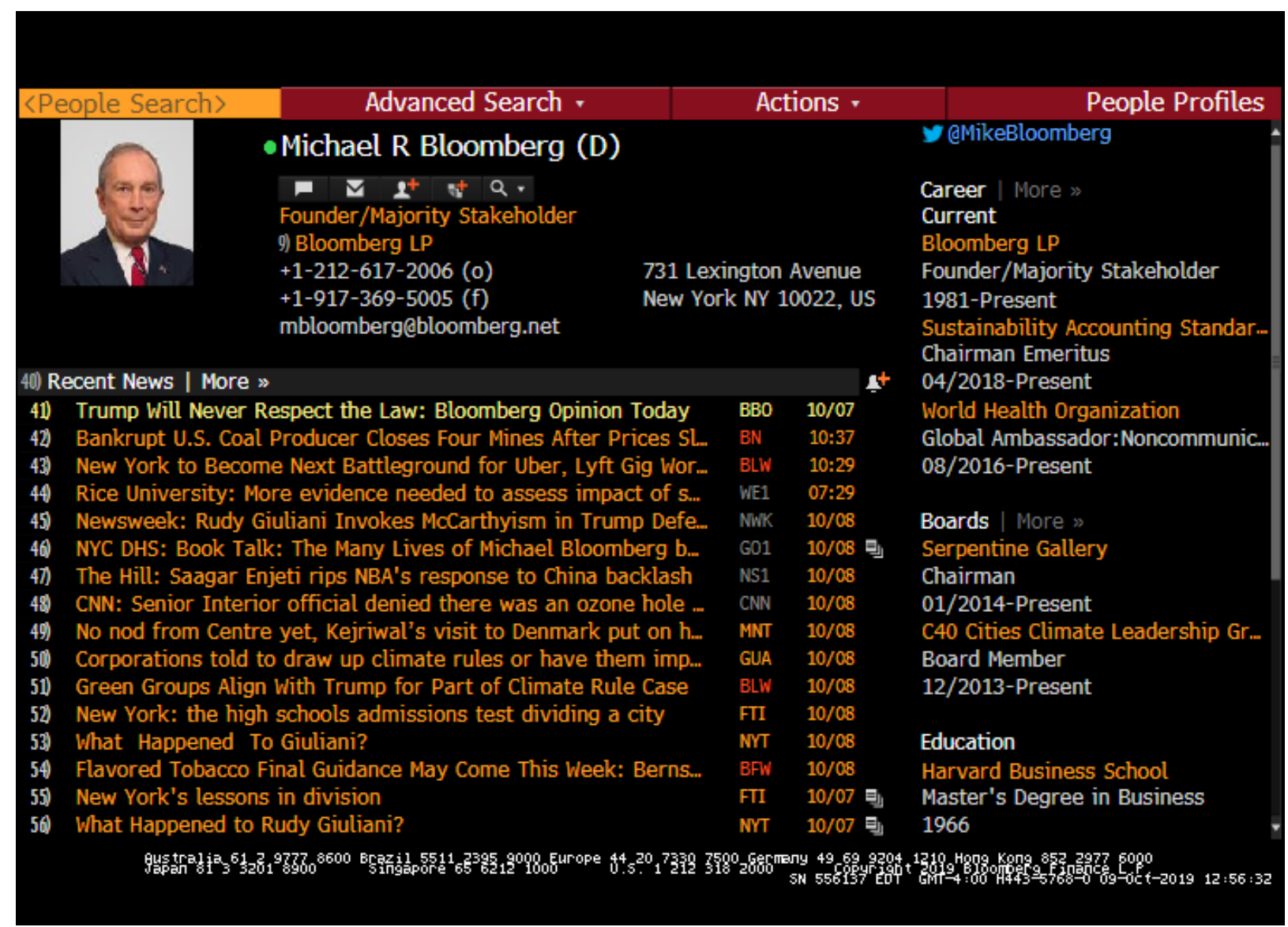




\section{Figure 2. Example of an Executive's Annual Terminal Activity}

This figure describes the Bloomberg terminal activity for a CFO in our sample. The $\mathrm{x}$-axis is each time (minute) during 24-hours. The y-axis measures the probability during the year that the CFO is active on the terminal at each time, given that the day is not a holiday and it is a weekday.

\section{Percent Active - by (Local) Time - Weekdays}

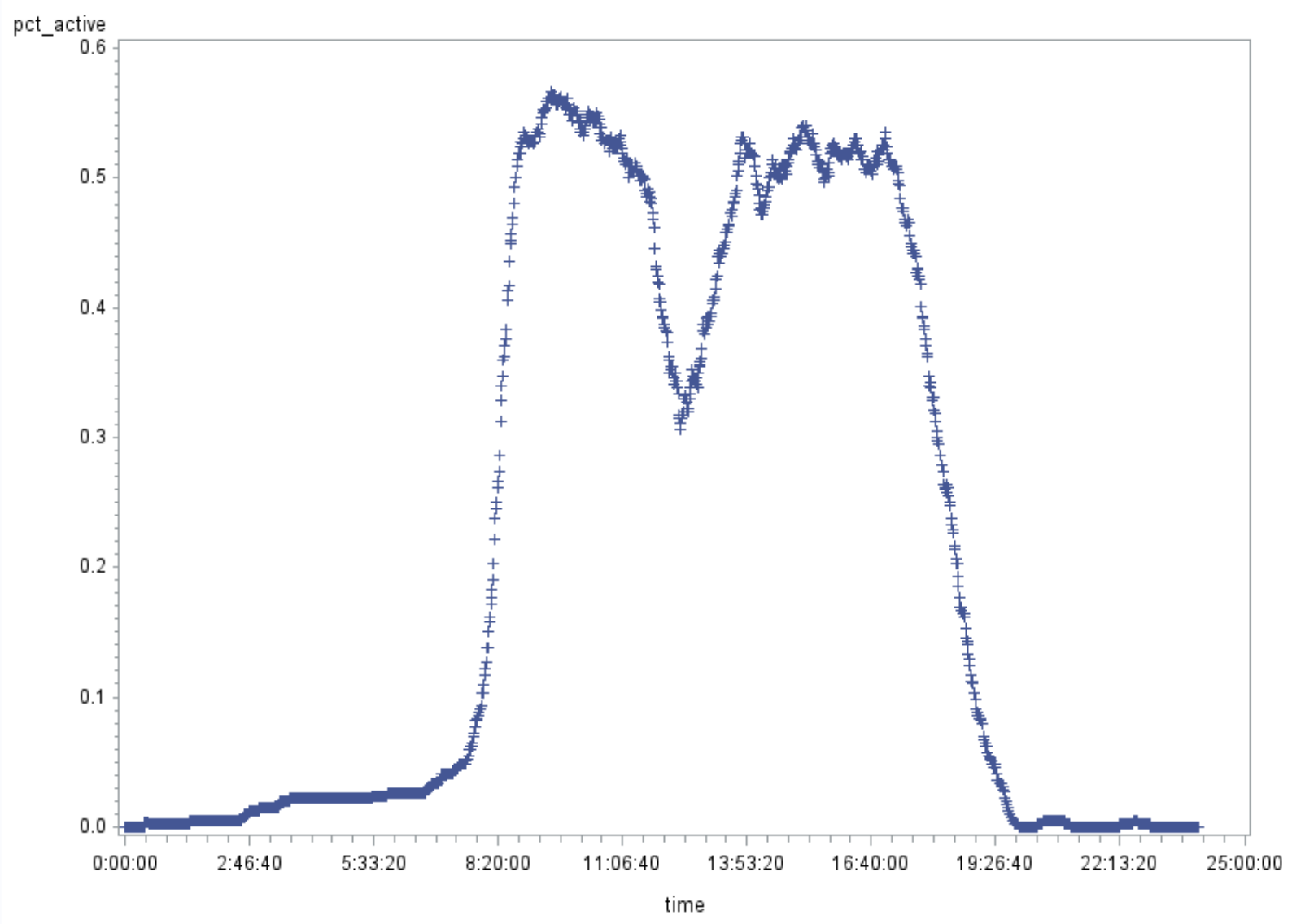




\section{Figure 3. Executive Intraday Terminal Activity}

The figure provides the average percentage of executives that are active on the Bloomberg terminal at a given time on weekdays (Monday through Friday) across the sample period. Panel A averages based on the Eastern time zone, while Panel B includes averages based on the local time zone of the Executive. Data are from Bloomberg.

Percent Active - by (Eastern) Time - Weekdays

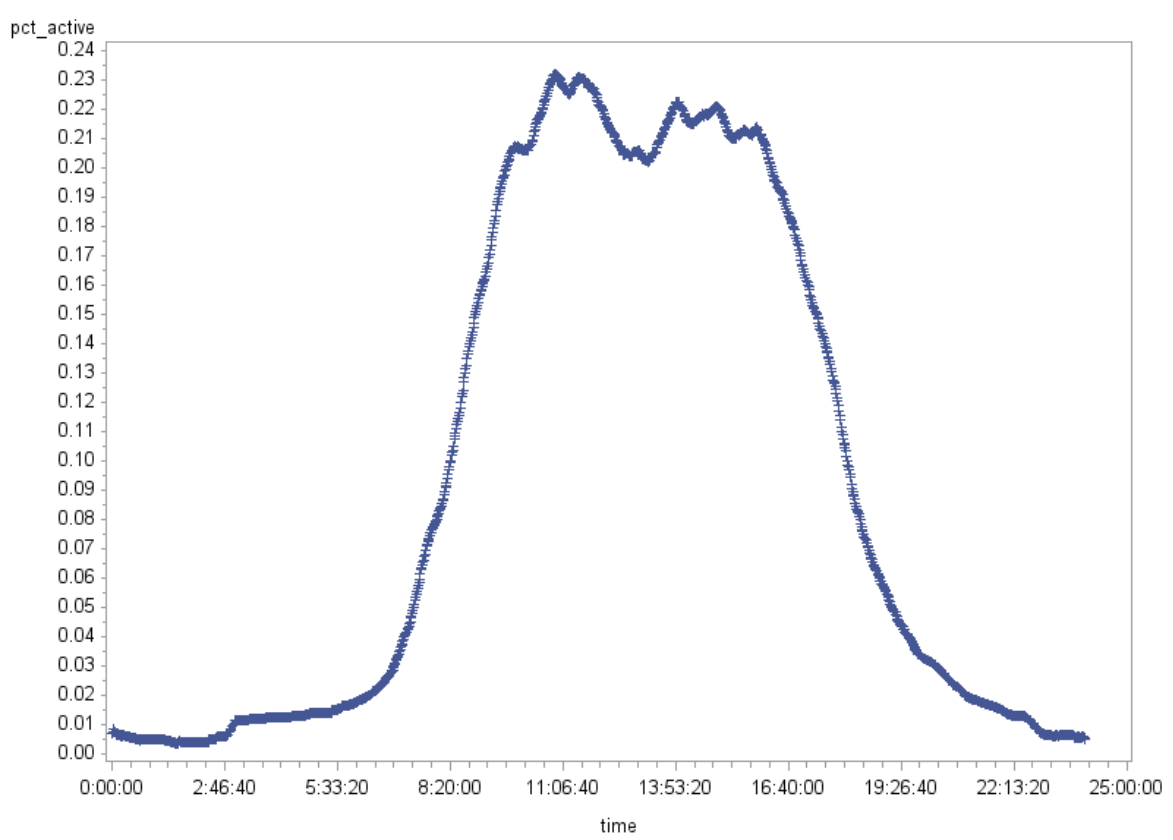

Percent Active - by (Local) Time - Weekdays

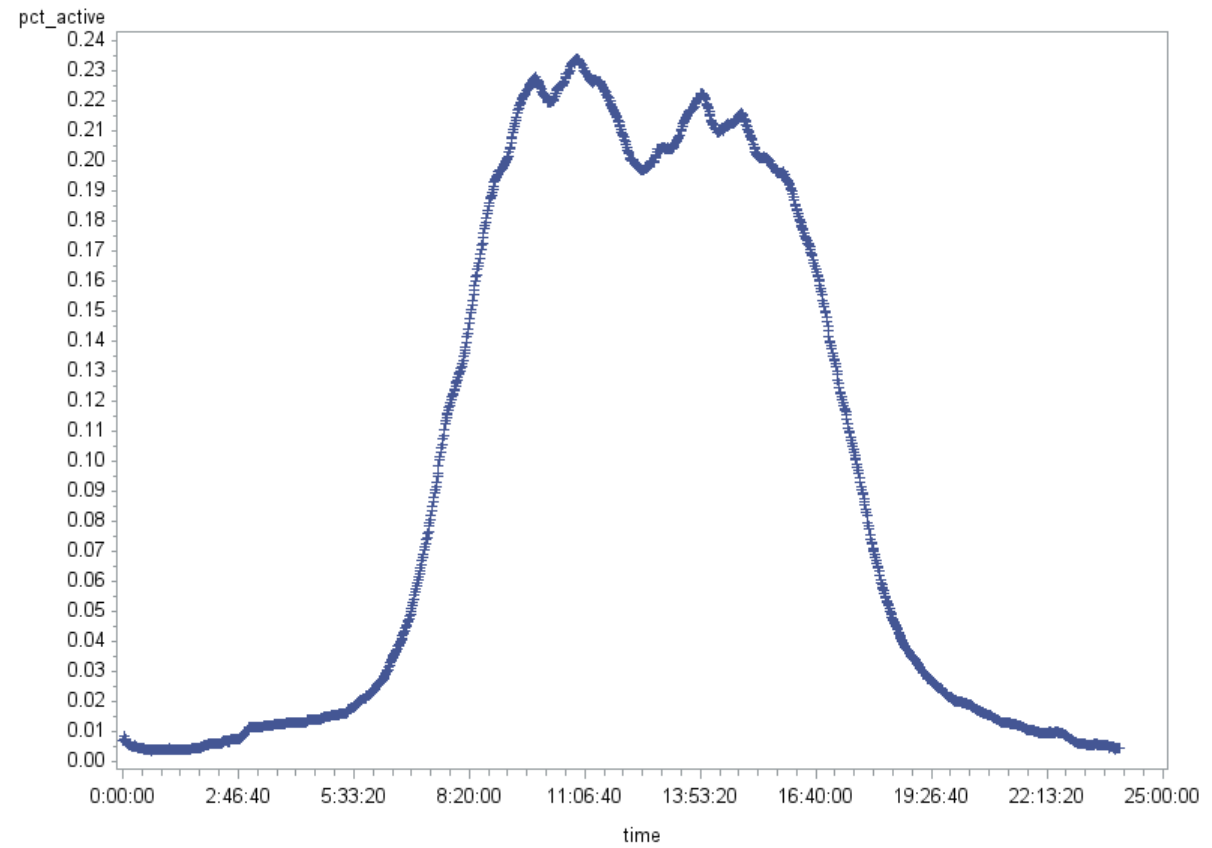




\section{Figure 4. Effort by Day of the Week}

The figure provides the average GML measure for each day of the week for the full sample.

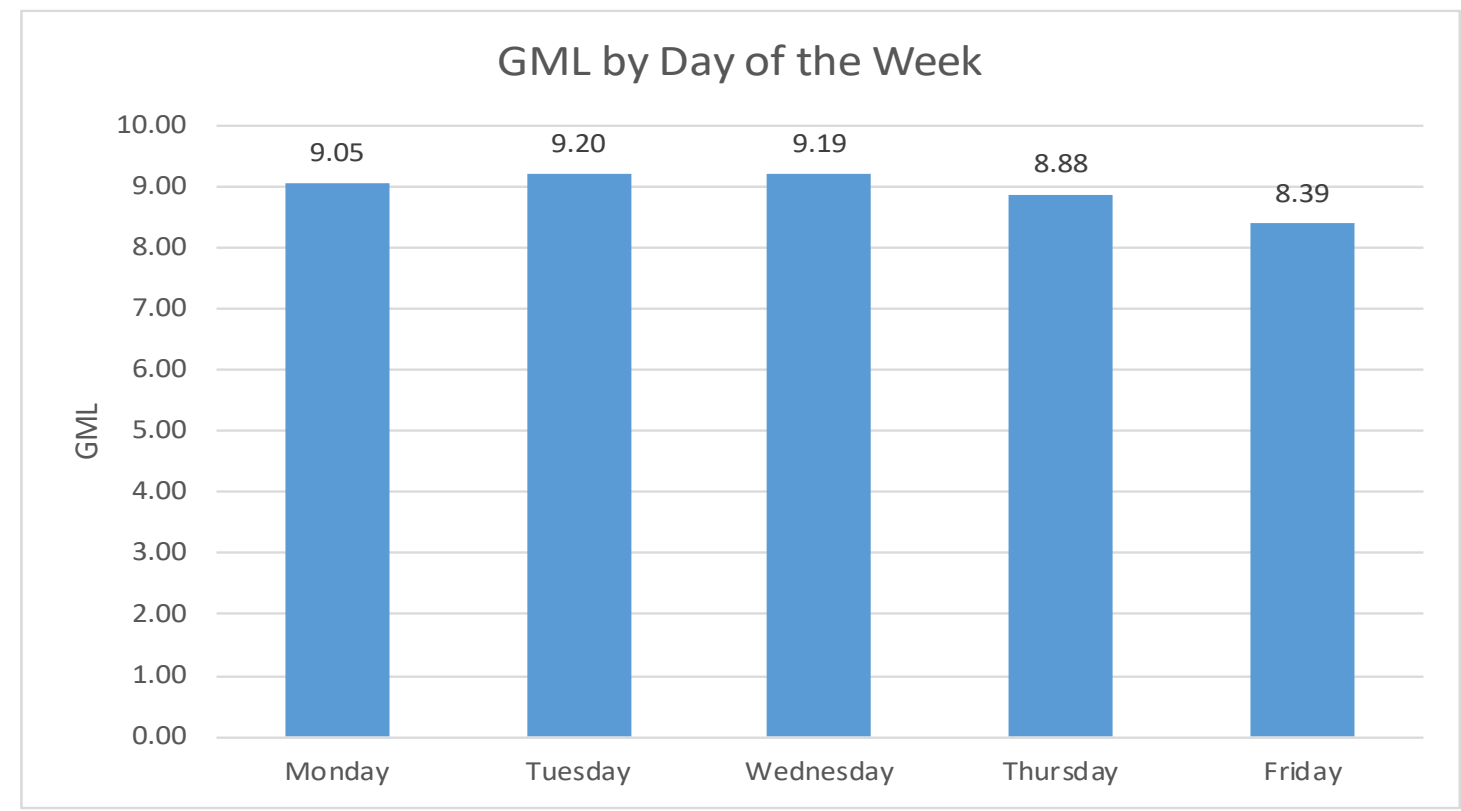

Figure 5. Executive Activity and the Earnings Announcement Cycle

The figure includes executive terminal activity through the quarter relative to the firm's earnings announcement. Effort is defined as hours online on the terminal. Panel A presents results for all executives in the sample while Panel B presents results for CFOs and Panel C presents results for CEOs.

\section{Panel 5A: Executive Activity}

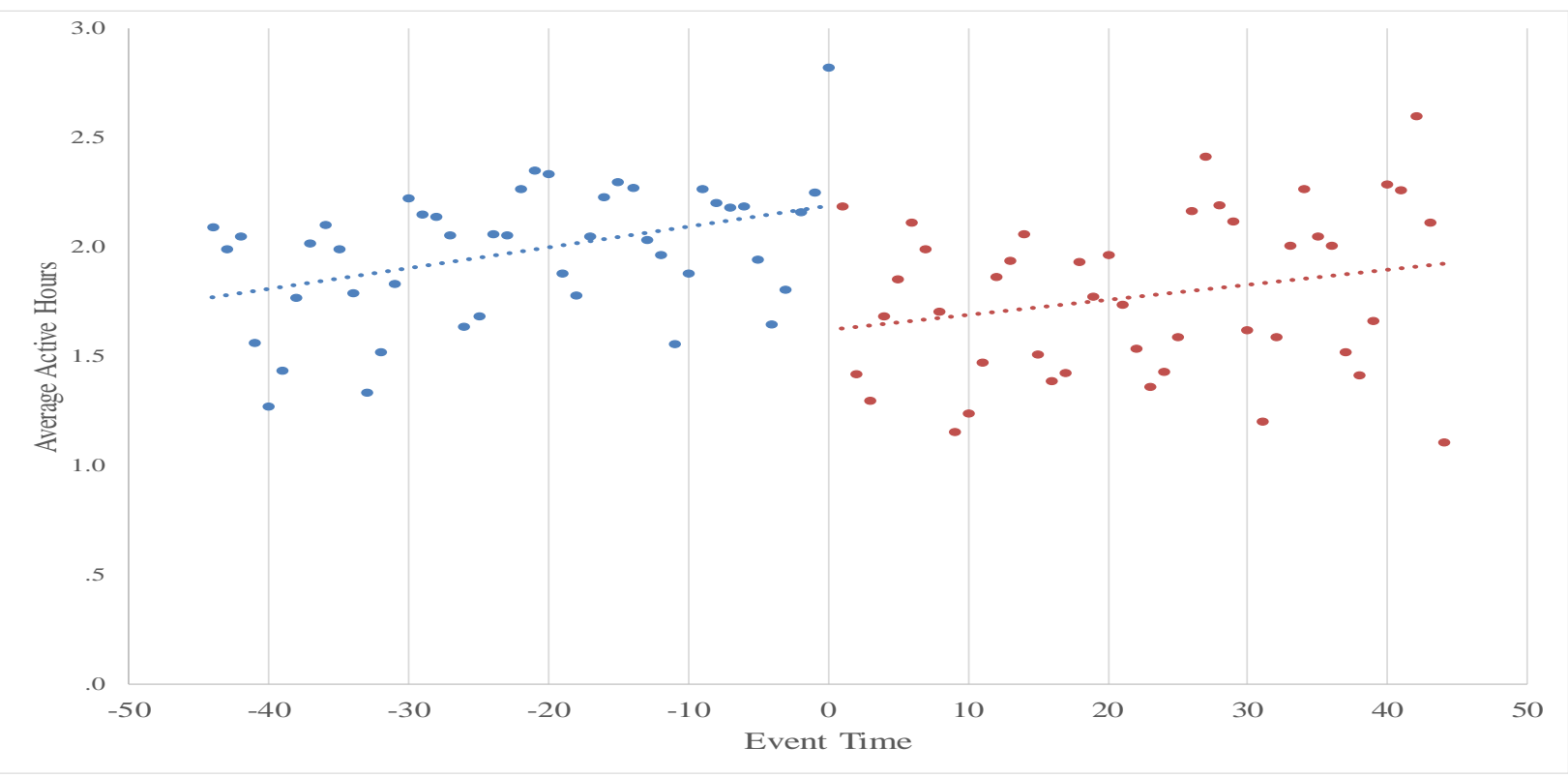




\section{Panel 5B: CFO Activity}

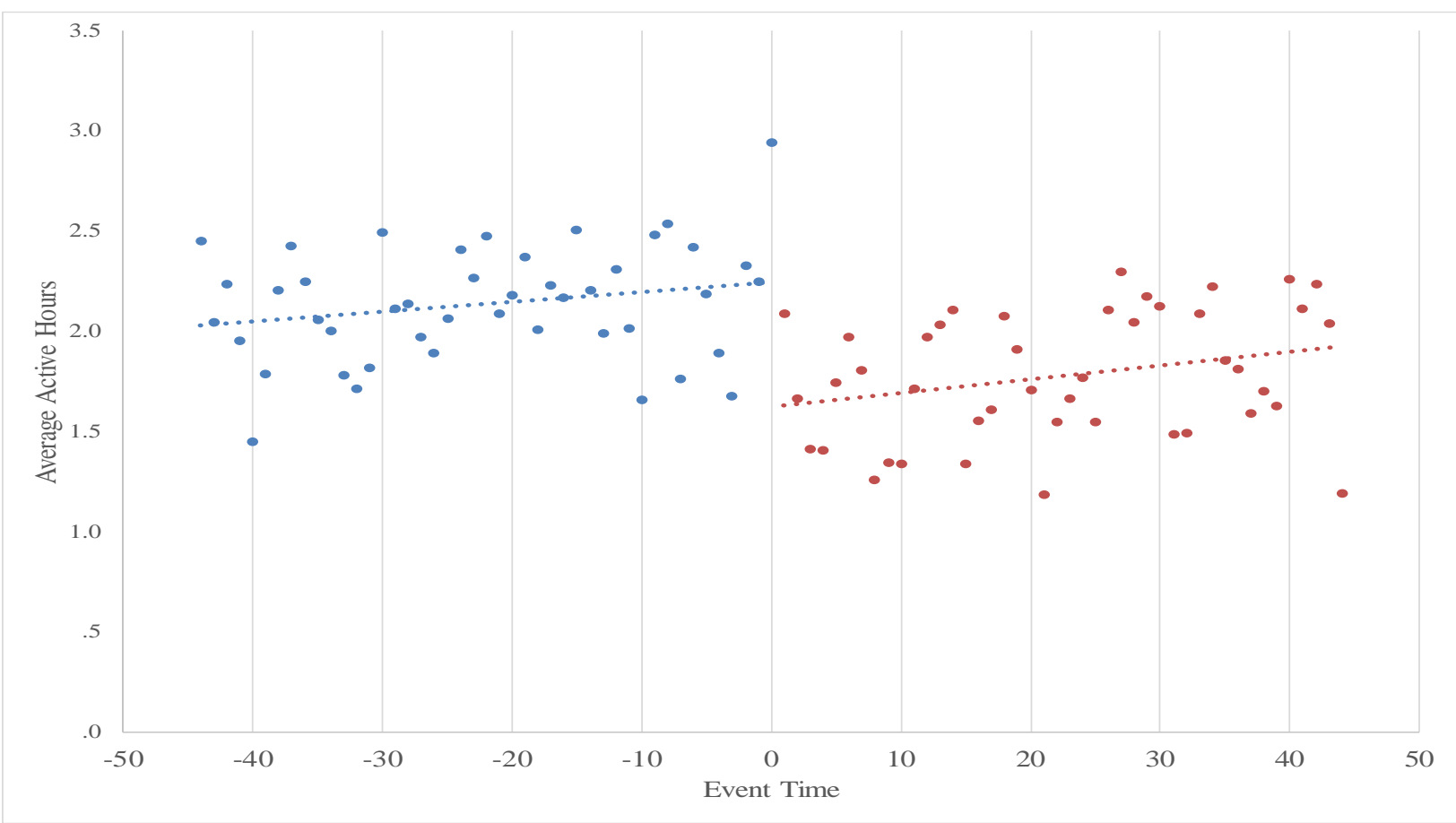

\section{Panel 5C: CEO Activity}

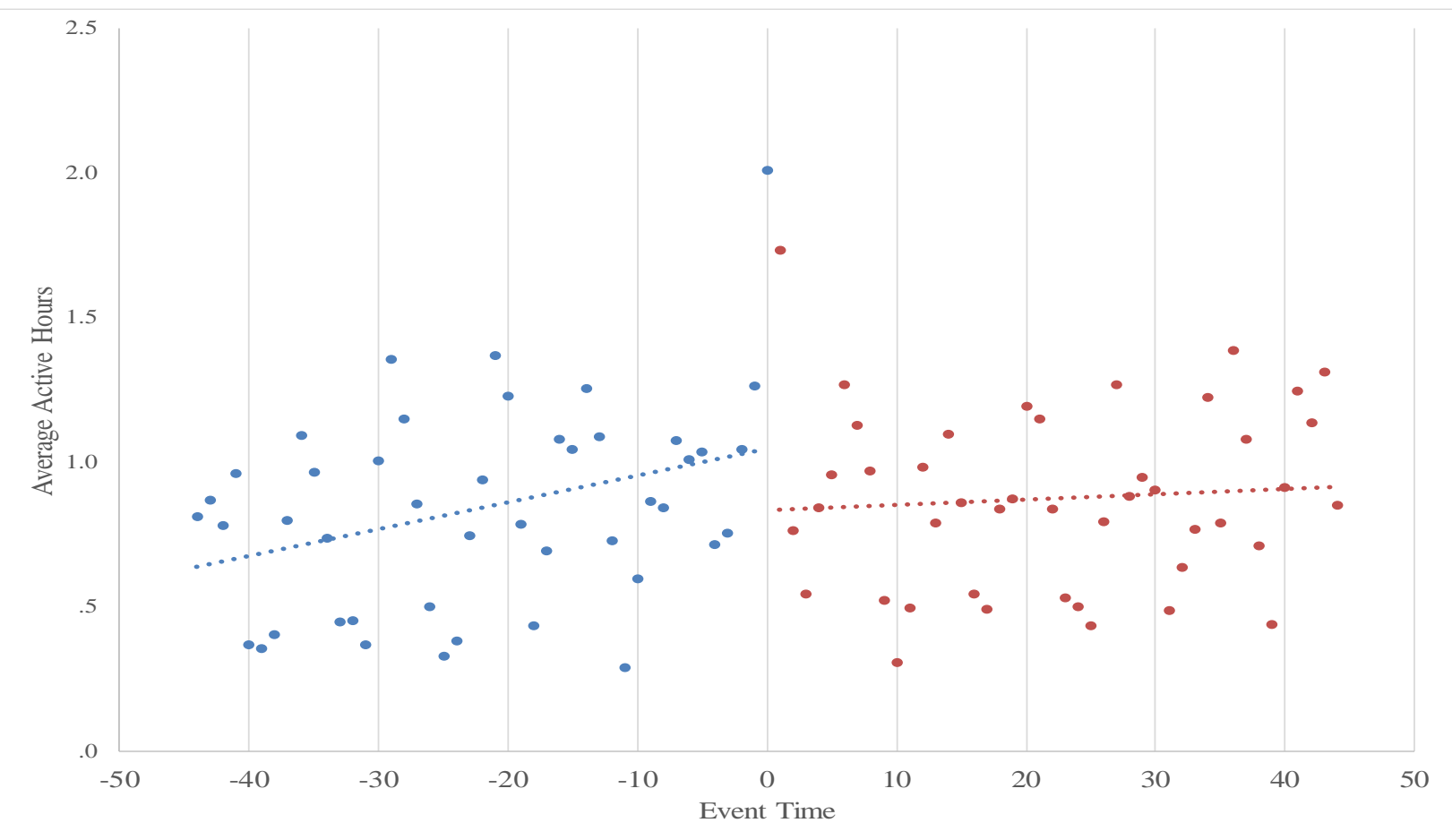




\section{Figure 6. Executive Intraday Terminal Activity during the COVID-19 Pandemic}

The figure provides the average percentage of executives that are active on the Bloomberg terminal at a given time on weekdays (Monday through Friday) for the months of March (Panel A), April (Panel B), May (Panel C), and June (Panel D) for the years 2018, 2019, and 2020. Averages are based on the local time zone. Data are from Bloomberg.

\section{Panel 6A - Activity during March}

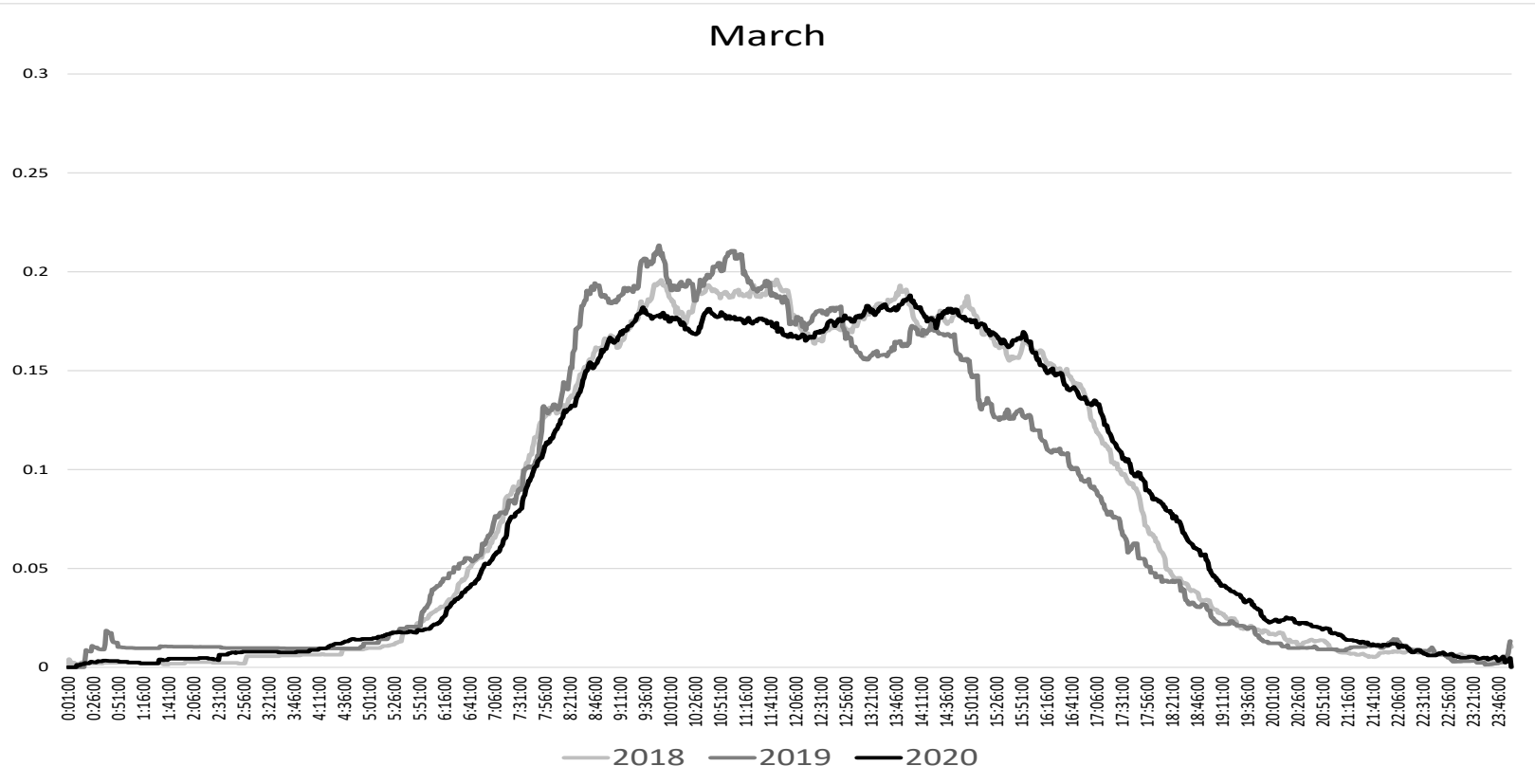

\section{Panel 6B - Activity during April}

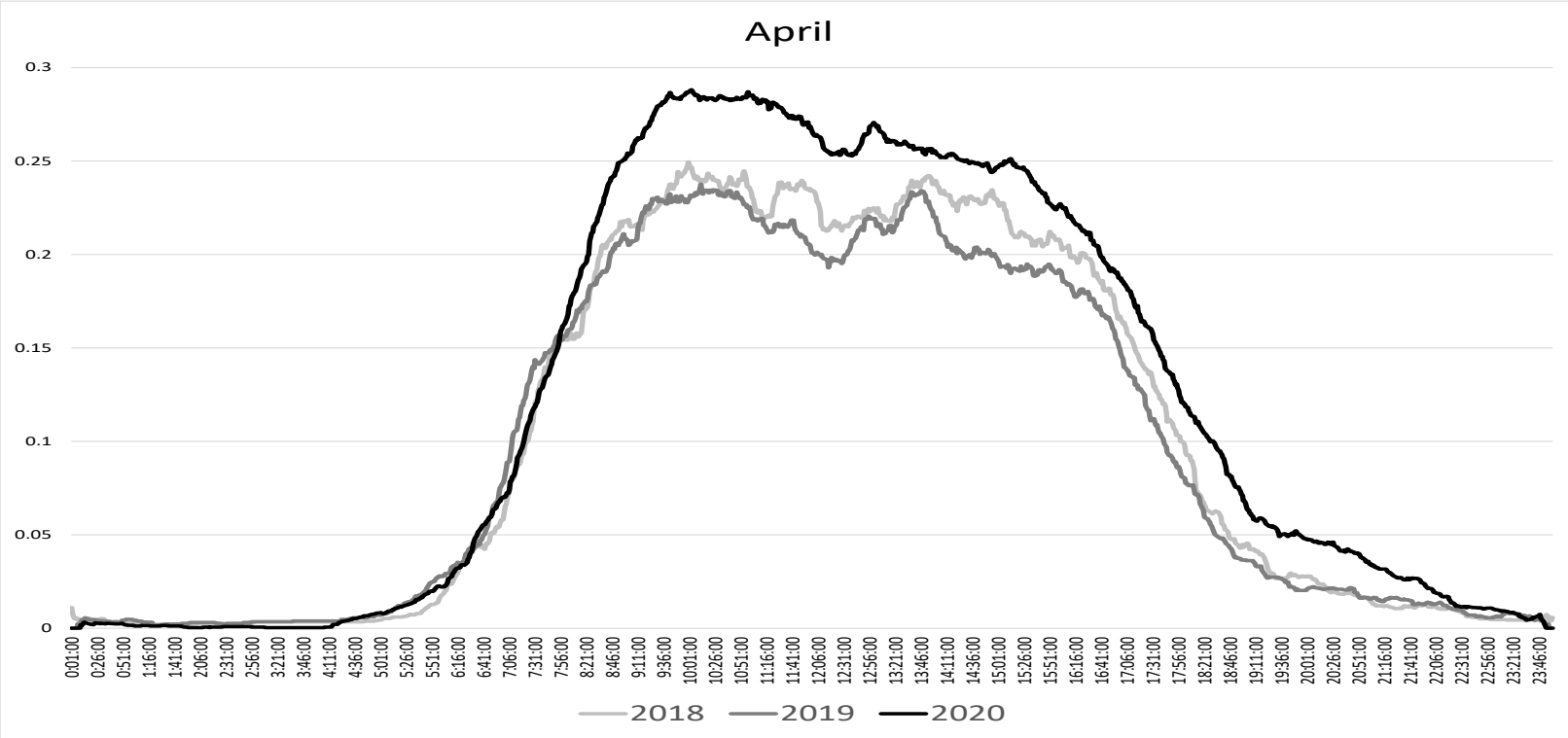




\section{Panel 6C - Activity during May}

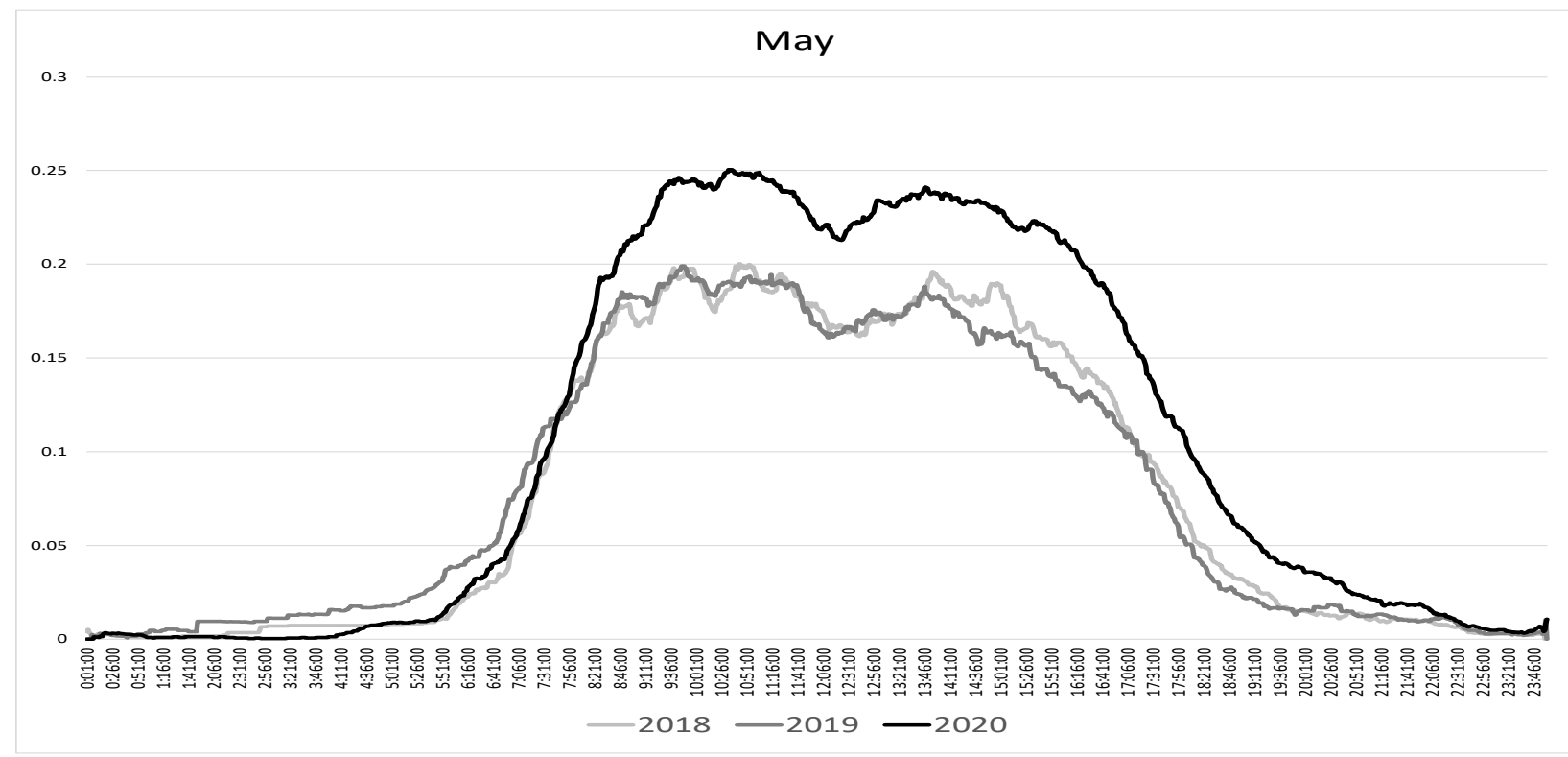

\section{Panel 6D - Activity during June}

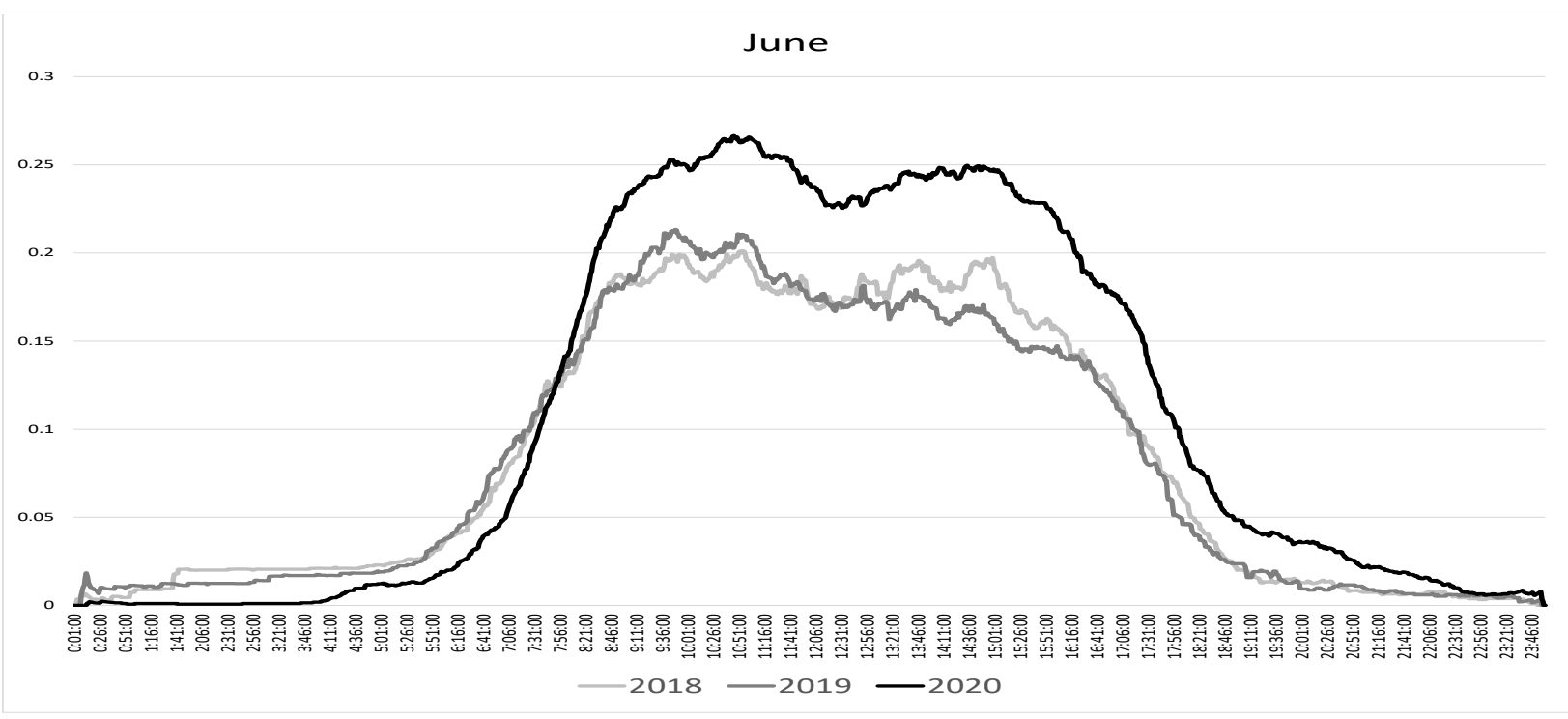




\section{Figure 7. Gaussian Mixture Length Examples}

The figure provides an example of the GML measure for three executive-year observations. The blue bars represent the empirical probability density function based on activity on Bloomberg. The red curve is the estimated Gaussian Mixture Model pdf using the iterative Expectation-Maximization (EM) algorithm. The two orange curves are the two underlying Gaussian pdfs. The dashed vertical bars are the estimated means of the two distributions. The two black lines represent the beginning and end of the GML measure, or the interval $\left(\mu_{1}-\sigma_{1}, \mu_{2}+\sigma_{2}\right)$.

\section{Panel 7.A - Example 1}

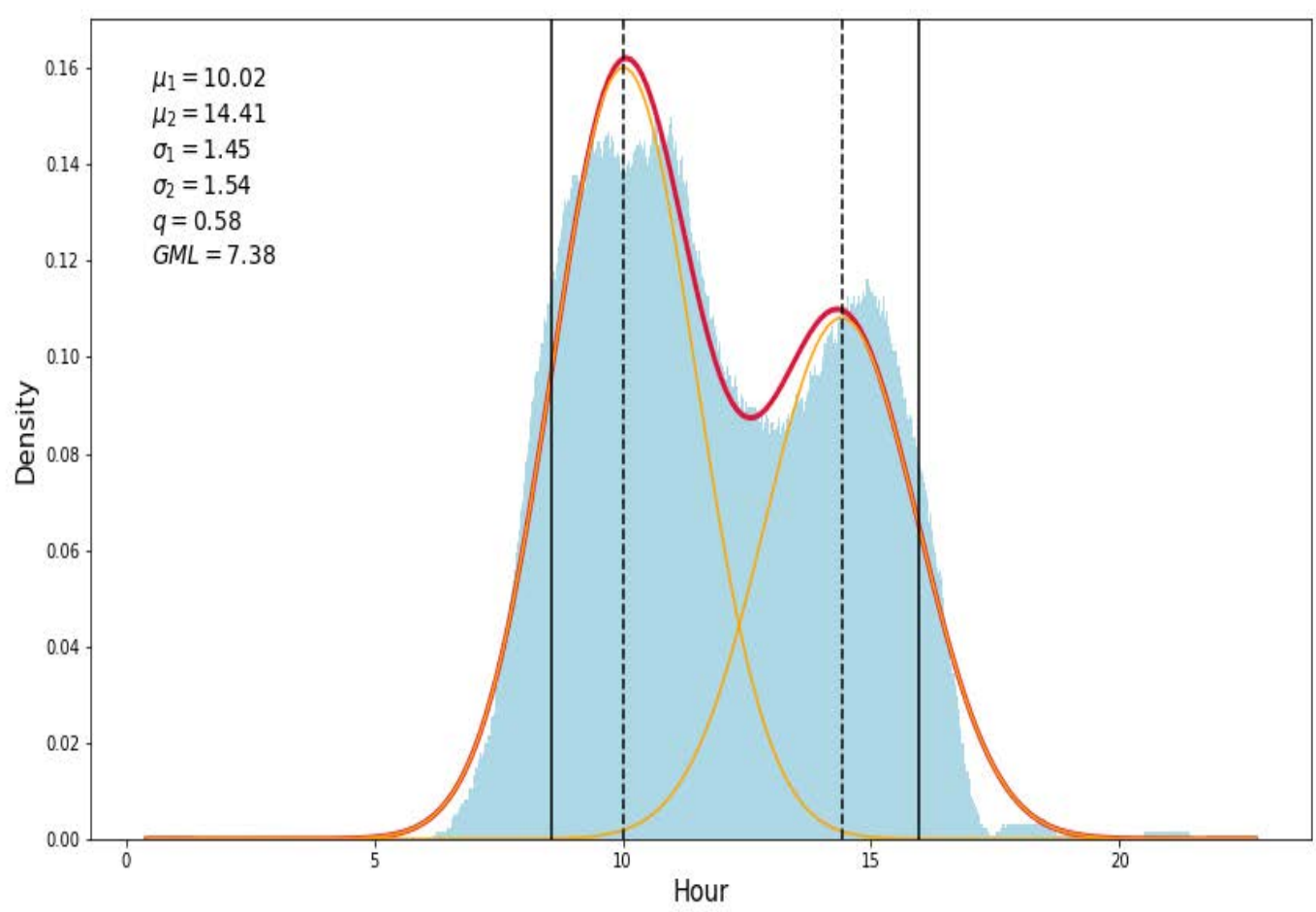




\section{Panel 7.B - Example 2}

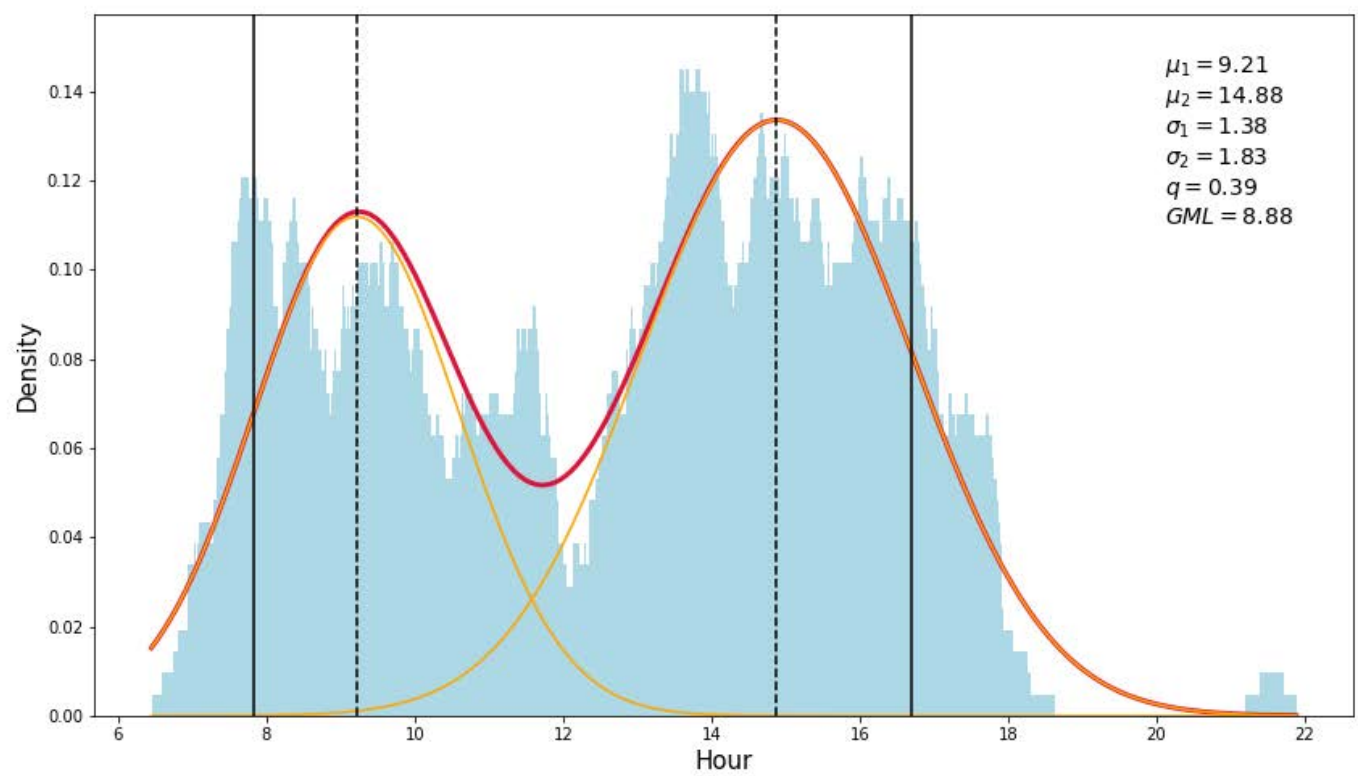

Panel 7.C - Example 3

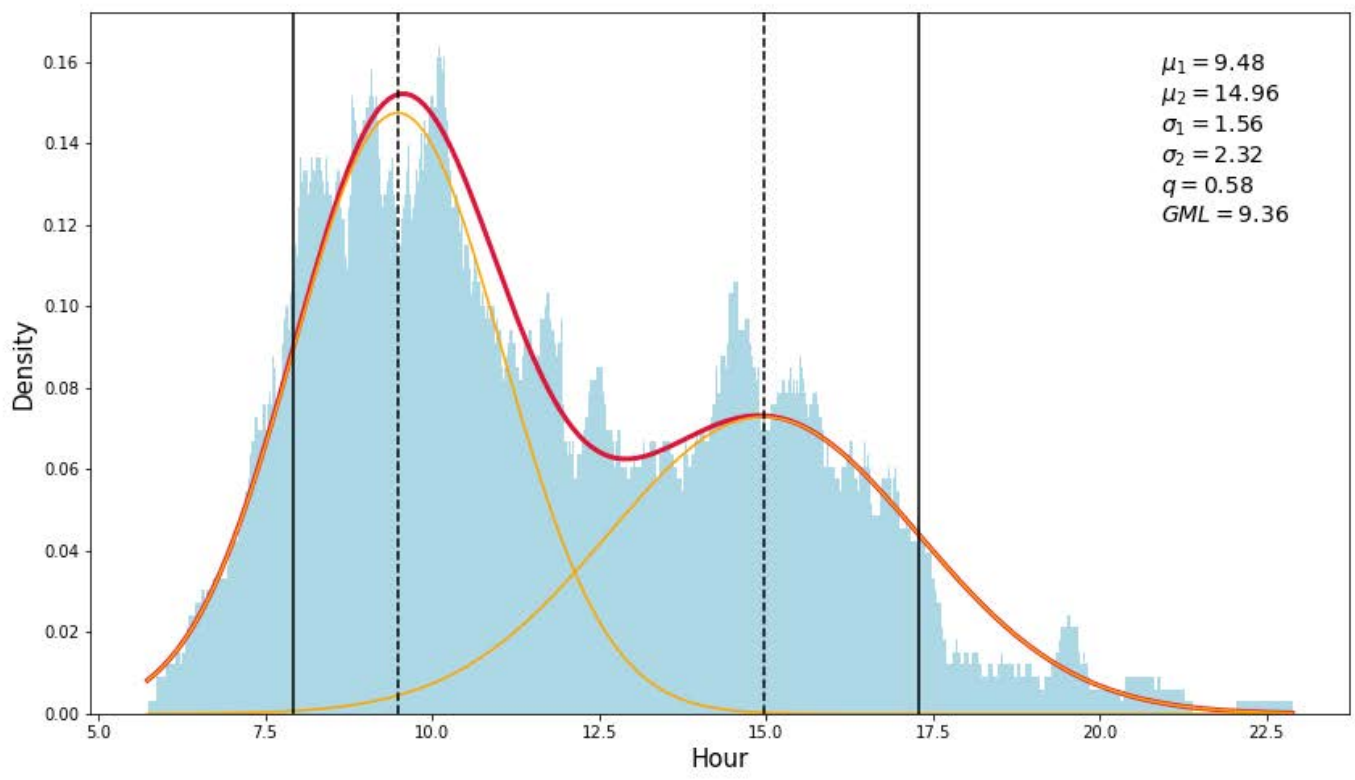




\section{Figure 8. Effort Measure Histogram}

The figure provides a histogram of the effort measure GML (Gaussian Mixture Length)

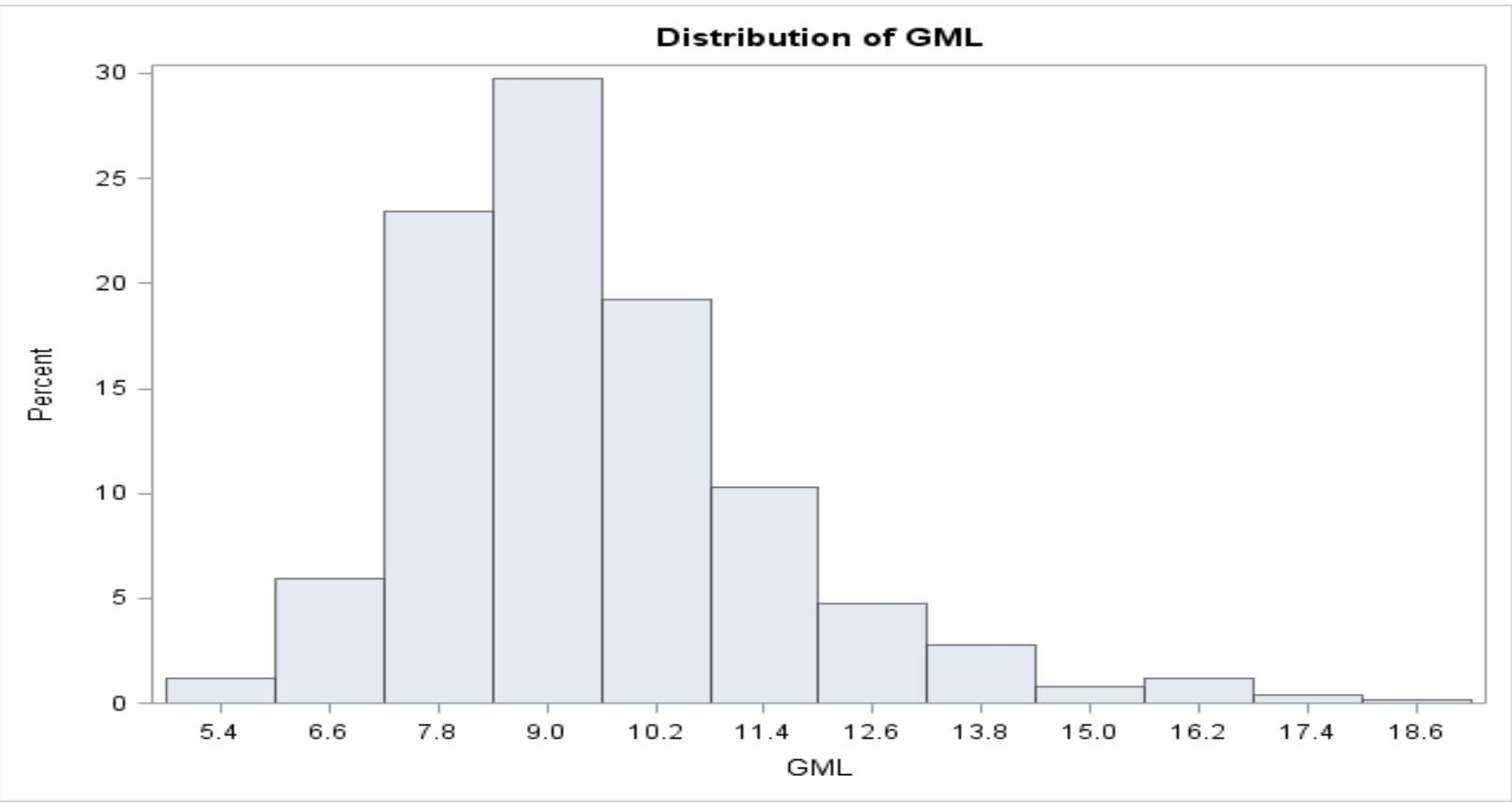




\section{Figure 9. Effort and Leisure}

This figure provides an example of the measure good_weather calculated monthly for 4 cities - San Diego, CA, Honolulu, HI, New York, NY, and Houston, TX. The variable good_weather is the percentage of hours during the month in which (a) the Universal Thermal Climate Index (UTCI) is in the "thermal comfort zone", (b) there is no precipitation, (c) the sky is not overcast, and (d) it is a daylight hour.

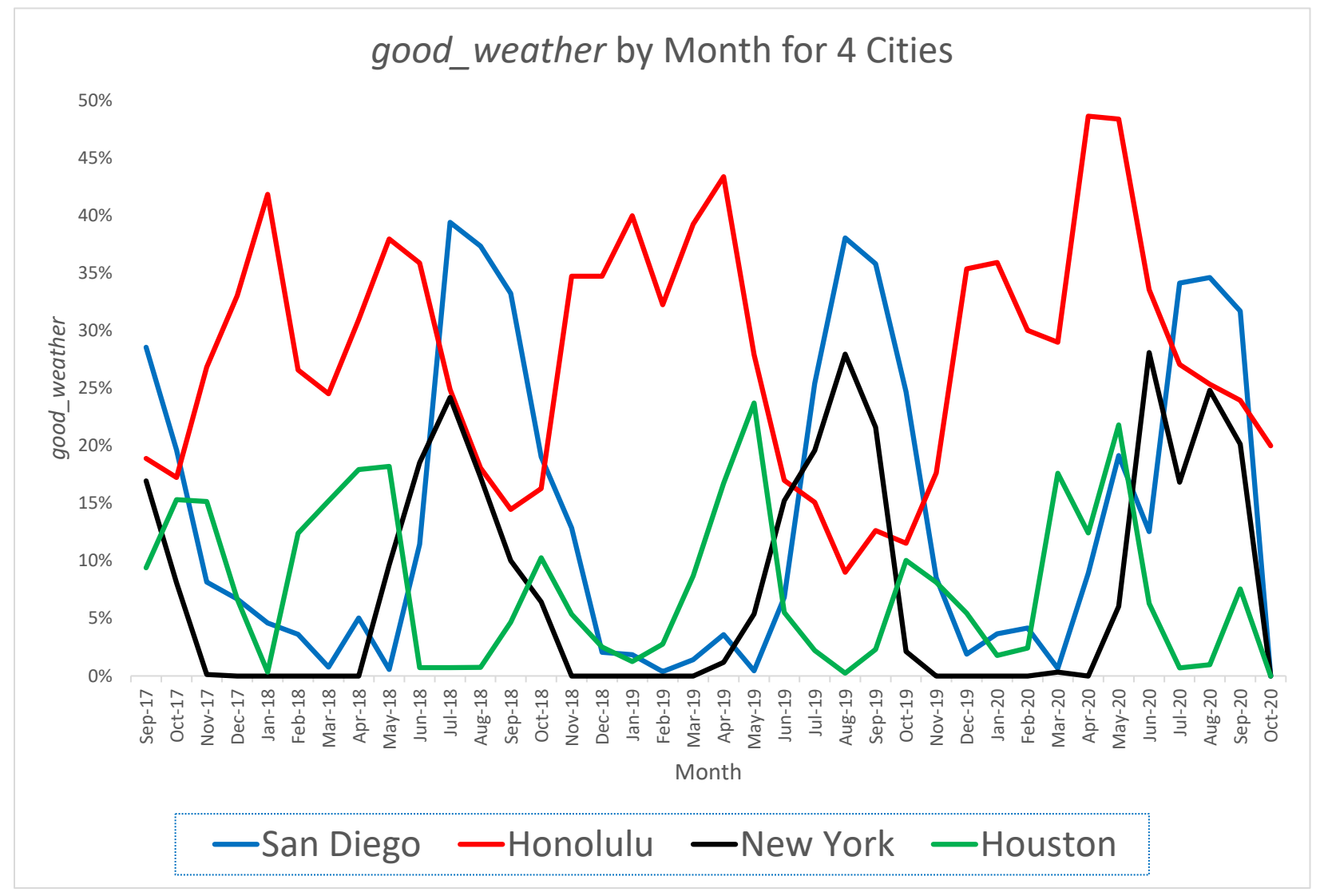

